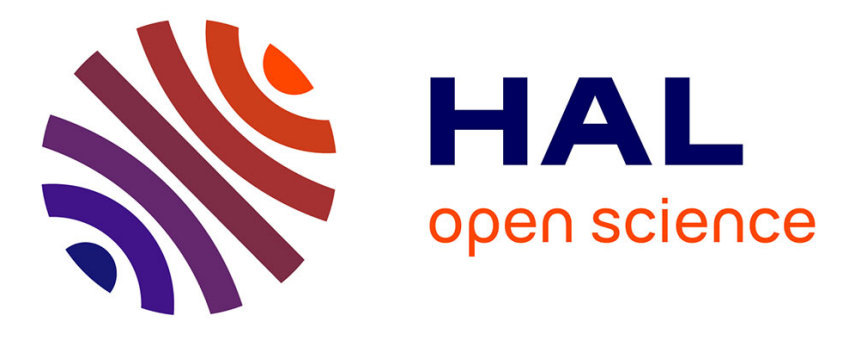

\title{
The atmospheric carbon and transport (ACT)-America mission
}

\author{
Kenneth Davis, Edward Browell, Sha Feng, Thomas Lauvaux, Michael \\ Obland, Sandip Pal, Bianca Baier, David Baker, Ian Baker, Zachary Barkley, \\ et al.
}

\section{To cite this version:}

Kenneth Davis, Edward Browell, Sha Feng, Thomas Lauvaux, Michael Obland, et al.. The atmospheric carbon and transport (ACT)-America mission. Bulletin of the American Meteorological Society, 2021, 102 (9), pp.E1714-E1734. 10.1175/BAMS-D-20-0300.1 . hal-03381213

\section{HAL Id: hal-03381213 https://hal.science/hal-03381213}

Submitted on 16 Oct 2021

HAL is a multi-disciplinary open access archive for the deposit and dissemination of scientific research documents, whether they are published or not. The documents may come from teaching and research institutions in France or abroad, or from public or private research centers.
L'archive ouverte pluridisciplinaire HAL, est destinée au dépôt et à la diffusion de documents scientifiques de niveau recherche, publiés ou non, émanant des établissements d'enseignement et de recherche français ou étrangers, des laboratoires publics ou privés. 


\title{
BAMS Article
}

\section{The Atmospheric Carbon and Transport (ACT)-America Mission}

Kenneth J. Davis, Edward V. Browell, Sha Feng, Thomas Lauvaux, Michael D. Obland, Sandip Pal, Bianca C. Baier, David F. Baker, Ian T. Baker, Zachary R. Barkley, Kevin W. Bowman, Yu Yan Cui, A. Scott Denning, Joshua P. DiGangi, Jeremy T. Dobler, Alan Fried, Tobias Gerken, Klaus Keller, Bing Lin, Amin R. Nehrir, Caroline P. Normile, Christopher W. O’Dell, Lesley E. Ott, Anke Roiger, Andrew E. Schuh, Colm Sweeney, Yaxing Wei, Brad Weir, Ming Xue, and Christopher A. Williams

\begin{abstract}
The Atmospheric Carbon and Transport (ACT)-America NASA Earth Venture Suborbital Mission set out to improve regional atmospheric greenhouse gas (GHG) inversions by exploring the intersection of the strong GHG fluxes and vigorous atmospheric transport that occurs within the midlatitudes. Two research aircraft instrumented with remote and in situ sensors to measure GHG mole fractions, associated trace gases, and atmospheric state variables collected 1,140.7 flight hours of research data, distributed across 305 individual aircraft sorties, coordinated within 121 research flight days, and spanning five 6 -week seasonal flight campaigns in the central and eastern United States. Flights sampled 31 synoptic sequences, including fair-weather and frontal conditions, at altitudes ranging from the atmospheric boundary layer to the upper free troposphere. The observations were complemented with global and regional GHG flux and transport model ensembles. We found that midlatitude weather systems contain large spatial gradients in GHG mole fractions, in patterns that were consistent as a function of season and altitude. We attribute these patterns to a combination of regional terrestrial fluxes and inflow from the continental boundaries. These observations, when segregated according to altitude and air mass, provide a variety of quantitative insights into the realism of regional $\mathrm{CO}_{2}$ and $\mathrm{CH}_{4}$ fluxes and atmospheric GHG transport realizations. The ACT-America dataset and ensemble modeling methods provide benchmarks for the development of atmospheric inversion systems. As global and regional atmospheric inversions incorporate ACT-America's findings and methods, we anticipate these systems will produce increasingly accurate and precise subcontinental GHG flux estimates.
\end{abstract}

KEYWORDS: Boundary layer; Synoptic-scale processes; Biosphere-atmosphere interaction; Carbon cycle; Greenhouse gases; Inverse methods

https://doi.org/10.1175/BAMS-D-20-0300.1

Corresponding author: Kenneth J. Davis, kjd10@psu.edu

In final form 21 April 2021

@2021 American Meteorological Society

For information regarding reuse of this content and general copyright information, consult the AMS Copyright Policy. 
AFFILIATIONS: Davis—Department of Meteorology and Atmospheric Science, and Earth and Environmental Systems Institute, The Pennsylvania State University, University Park, Pennsylvania; Browell—STARSSIII Affiliate, NASA Langley Research Center, Hampton, Virginia; Feng,* Barkley, Cui,* Gerken,* and Normile*-Department of Meteorology and Atmospheric Science, The Pennsylvania State University, University Park, Pennsylvania; Lauvaux_Laboratoire des sciences du climat et de l'environnement, Université Paris-Saclay, CNRS, CEA, UVSQ, CEA-Saclay, I'Orme des Merisiers, Gif-sur-Yvette, France; Obland, DiGangi, Lin, and Nehrir-NASA Langley Research Center, Hampton, Virginia; Pal-Atmospheric Science Division, Texas Tech University, Lubbock, Texas; Baier-Cooperative Institute for Research in Environmental Sciences, University of Colorado Boulder, and NOAA/Global Monitoring Laboratory, Boulder, Colorado; D. F. Baker, I. T. Baker, O'Dell, and Schuh-Cooperative Institute for Research in the Atmosphere, Colorado State University, Fort Collins, Colorado; Bowman-Jet Propulsion Laboratory, California Institute of Technology, Pasadena, California; Denning-Department of Atmospheric Science, Colorado State University, Fort Collins, Colorado; Dobler-Spectral Sensor Solutions LLC, Fort Wayne, Indiana; Fried_-Institute of Arctic and Alpine Research, University of Colorado Boulder, Boulder, Colorado; Keller-Department of Geosciences, and Earth and Environmental Systems Institute, The Pennsylvania State University, University Park, Pennsylvania; Ott-NASA Goddard Space Flight Center, Greenbelt, Maryland; Roiger-Deutsches Zentrum für Luft- und Raumfahrt, Institut für Physik der Atmosphäre, Oberpfaffenhofen, Germany; Sweeney—NOAA/Global Monitoring Laboratory, Boulder, Colorado; Wei-Environmental Sciences Division, Oak Ridge National Laboratory, Oak Ridge, Tennessee; WeirUniversities Space Research Association, Columbia, and NASA Goddard Space Flight Center, Greenbelt, Maryland; Xue-Center for Analysis and Prediction of Storms, and School of Meteorology, University of Oklahoma, Norman, Oklahoma; Williams-Graduate School of Geography, Clark University, Worcester, Massachusetts

* CURRENT AFFILIATIONS: Feng-Atmospheric Sciences and Global Change Division, Pacific Northwest National Laboratory, Richland, Washington; Cui-California Air Resources Board, Sacramento, California; Gerken—School of Integrated Sciences, James Madison University, Harrisonburg, Virginia; NormileBipartisan Policy Center, Washington, D.C.

U nderstanding the terrestrial carbon cycle is essential for diagnosing current and predicting future climate change (Marquis and Tans 2008; Gregory et al. 2009; Michalak et al. 2011). Our current understanding of Earth's carbon cycle is limited. We know global anthropogenic carbon dioxide $\left(\mathrm{CO}_{2}\right)$ emissions with good accuracy, and that Earth's terrestrial biosphere has been a strong net sink of atmospheric $\left(\mathrm{CO}_{2}\right)$ for more than three decades (Ciais et al. 2013) slowing the accumulation of $\mathrm{CO}_{2}$ caused by fossil fuel burning. The causes of these biogenic $\mathrm{CO}_{2}$ sinks (Huntzinger et al. 2017), their location (Peylin et al. 2013; Crowell et al. 2019), and their likely evolution in the future (Friedlingstein et al. 2014), remain deeply uncertain, contributing considerable uncertainty to climate projections (IPCC 2013; Friedlingstein et al. 2014; Holden et al. 2018). Terrestrial biosphere models of ecosystem-atmosphere $\mathrm{CO}_{2}$ exchange diverge substantially in their regional simulations of gross primary productivity (GPP) and ecosystem respiration (RE), and show large differences in net ecosystem-atmosphere exchange of $\mathrm{CO}_{2}$ (NEE) at seasonal and annual time scales (Huntzinger et al. 2012; Fisher et al. 2014; Schwalm et al. 2015).

Methane $\left(\mathrm{CH}_{4}\right)$ is accumulating in the atmosphere (Montzka et al. 2011; Dlugokencky et al. 2011) and is the second largest contributor to contemporary anthropogenic climate change (Myhreetal. 2013). Fluctuations in the global rate of increase of atmospheric $\mathrm{CH}_{4}$ (Nisbet etal. 2014) remain unexplained (Turner et al. 2019). Anthropogenic $\mathrm{CH}_{4}$ emissions from inventories have been shown to have large biases (e.g., Miller et al. 2013; Alvarez et al. 2018), but these biases are not clearly related to the fluctuations (Bruhwiler et al. 2017; Lan et al. 2019). Estimates of wetland $\mathrm{CH}_{4}$ emissions diverge by nearly a factor of 2 on a global scale (Saunois et al. 2016) and by more than a factor of 4 in North America (Bloom et al. 2017). 
How can atmospheric inversions help? Atmospheric inversions have the potential to provide ongoing, accurate and precise diagnoses of $\mathrm{CO}_{2}$ and $\mathrm{CH}_{4}$ fluxes. Atmospheric inversions (e.g., Baker et al. 2006a, 2010; Peters et al. 2007; Lauvaux et al. 2012; Peylin et al. 2013; Crowell et al. 2019) combine a first guess of fluxes (e.g., a model of ecosystem respiration and photosynthesis), referred to as a prior flux estimate, with winds and vertical mixing from an atmospheric transport reanalysis. The prior fluxes are propagated through the atmospheric transport fields to predict space-time distributions of atmospheric $\mathrm{CO}_{2}$ and $\mathrm{CH}_{4}$ (hereafter collectively referred to as $\mathrm{C}$ ) concentrations (hereafter we will use the more precise term of mole fraction). The simulated $\mathrm{C}$ mole fractions are then compared to observations, such as those collected by the Global Greenhouse Gas Reference Network (GGGRN; Conway et al. 1994; Dlugokencky et al. 2005; Andrews et al. 2014; Sweeney et al. 2015) or satellite platforms (Yokota et al. 2009; Kuze et al. 2016; Crisp et al. 2017; Hu et al. 2018; Eldering et al. 2019). The $\mathrm{C}$ flux estimates are then adjusted to minimize the difference between the observed and modeled atmospheric $\mathrm{C}$ mole fractions.

Challenges facing atmospheric inversions. Atmospheric inversions provide invaluable insights into global to zonal, decadal-scale sources and sinks of C (e.g., Tans et al. 1990; Ciais et al. 1995; Battle et al. 2000; Bousquet et al. 2006). Atmospheric inversions still struggle, however, to inform regional-scale C fluxes (Peylin et al. 2013; Crowell et al. 2019). Our limited understanding of Earth's carbon cycle stems arguably from our limited ability to diagnose routinely Earth-atmosphere fluxes at regional scales. Regional scales are critically important because they are the scales over which changes in the environment (e.g., climate, nutrients, insects, fire) and human activity (e.g., energy systems, land use, and land cover) drive changes in terrestrial C fluxes.

A growing observational network. Globally comparable, spatially and temporally extensive and dense atmospheric $\mathrm{C}$ measurements are essential for inferring Earthatmosphere fluxes of $\mathrm{C}$ using atmospheric inversions. Relevant spatial and temporal differences in atmospheric $\mathrm{C}$ are small, setting stringent demands on measurement calibration (Crotwell and Steinbacher 2018). Despite these challenges, the global observational network for atmospheric $\mathrm{C}$ is growing, bringing the potential for greater atmospheric constraint on regional $\mathrm{C}$ fluxes.

The most dramatic recent increases in observations have come from satellite remote sensing, including the Greenhouse gases Observing Satellite (GOSAT; Yokota et al. 2009; Kuze et al. 2016), the Orbiting Carbon Observatory 2 (OCO-2) and Orbiting Carbon Observatory 3 (OCO-3; Crisp et al. 2017; Eldering et al. 2019), the Tropospheric Monitoring Instrument (TROPOMI; Hu et al. 2018), and the Cross-Track Infrared Sounder (CrIS; Nalli et al. 2020). GeoCarb, planned for launch in 2022, will measure $\mathrm{CO}_{2}, \mathrm{CH}_{4}$, and $\mathrm{CO}$ over the Americas from geostationary orbit (Moore et al. 2018; Polonsky et al. 2014). Evaluation of space-based measurements remains a significant challenge. Considerable progress has been made on this topic (O'Dell et al. 2018), but evaluation has been largely limited to single-point observations (Wunch et al. 2011, 2017). Long-term, in situ measurement networks have also expanded in recent decades, including tower-based (Andrews et al. 2014; Miles et al. 2012; Hazan et al. 2016) and airborne (Sweeney et al. 2015; Machida et al. 2008) monitoring.

Atmospheric inversion systems have been adapted to include the expanded remote and in situ observation networks, with some success at determining regional C fluxes (e.g., Hu et al. 2019; Liu et al. 2017; Schuh et al. 2013). Nevertheless, large uncertainties remain in North American total $\mathrm{CH}_{4}$ and biogenic $\mathrm{CO}_{2}$ fluxes (Bruhwiler et al. 2017; USGCRP 2018; Crowell et al. 2019). Why, given the relatively high density of observations available in North America, do large uncertainties in $\mathrm{C}$ fluxes persist? 
Prior fluxes. Two factors beyond atmospheric observations limit the accuracy of atmospheric inversions. One is uncertainty in prior flux estimates. Atmospheric inversions are complex optimizations that can be strongly influenced, especially when atmospheric C data are limited, by their "first guess" or prior fluxes. Large biases and poorly quantified uncertainties in these prior fluxes will hinder atmospheric inverse $C$ flux estimates.

The importance of atmospheric transport. Uncertainty in atmospheric transport is a second major source of uncertainty in inverse flux estimates (Baker et al. 2006b; Stephens et al. 2007; Gerbig et al. 2008; Chevallier et al. 2010; Lauvaux and Davis 2014; Díaz-Isaac et al. 2018; Schuh et al. 2019). Atmospheric transport uncertainty in inverse estimates of net biogenic $\mathrm{CO}_{2}$ fluxes for temperate North America is 0.3-0.5 $\mathrm{PgC} \mathrm{yr}^{-1}$ (Gurney et al. 2002; Baker et al. 2006b; Schuh et al. 2019), nearly equal to the estimated magnitude of the net annual flux. What are the causes of this uncertainty, and what can be done to quantify and reduce it?

Improved representation of midlatitude weather systems in atmospheric inversions is highly likely to improve the resulting inverse $\mathrm{C}$ flux estimates. Midlatitude weather systems are both important drivers of the global redistribution of atmospheric C (Parazoo et al. 2008, 2011, 2012; Chan et al. 2008; Barnes et al. 2016; Schuh et al. 2019), and major drivers of regional atmospheric $\mathrm{C}$ patterns that carry regional $\mathrm{C}$ flux information (Hurwitz et al. 2004; Barkley et al. 2019a; Pal et al. 2020a; Hu et al. 2021). Midlatitude cyclones create north-south exchange of $\mathrm{C}$ in the cyclonic circulation, large-scale vertical lifting at frontal boundaries, and vertical mixing via convective instability (Parazoo et al. 2008, 2011; Samaddar et al. 2021).

Improving the resolution of the atmospheric models used in inverse modeling systems may reduce transport errors. Agustí-Panareda et al. (2019) used a global weather forecasting system to show that increasing the resolution of an atmospheric transport simulation reduces model-data errors in atmospheric $\mathrm{CO}_{2}$. Regional studies with high-density in situ atmospheric observation networks and regional, mesoscale atmospheric models (Lauvaux et al. 2012; Schuh et al. 2013) have inferred regional biogenic $\mathrm{CO}_{2}$ fluxes to an uncertainty level capable of evaluating agricultural inventories (Ogle et al. 2015). Hu et al. (2019) showed success in deriving temporal variations in North American biogenic $\mathrm{CO}_{2}$ fluxes using a continental-scale mesoscale modeling system. Regional inversion systems are still relatively rare. The resolution of global inversions is increasing, and the native atmospheric transport reanalyses used in these systems may already be sufficiently resolved to simulate $C$ transport by synoptic weather systems with good fidelity.

Data are needed to evaluate and improve the representation of weather systems in atmospheric inversions, and quantify the remaining transport uncertainty. Current long-term observational systems, in situ and remote, do not have sufficient spatial resolution and coverage to describe the spatial structures of $\mathrm{C}$ within midlatitude weather systems, and thus have limited ability to evaluate atmospheric simulations of $C$ transport by weather systems.

Value of an airborne mission. Atmospheric Carbon and Transport (ACT)-America is a regional-scale, weather-focused airborne mission working toward the development of a new generation of high-resolution, weather-resolving, ensemble-based atmospheric C inversion systems. The mission was conducted in the central and eastern United States, a region of strong, seasonal $\mathrm{C}$ fluxes and weather that includes relatively dense long-term $\mathrm{C}$ and weather observing networks. This mission complements long-term, global-scale observations such as those made by the NOAA Global Greenhouse Gas Reference Network and the growing constellation of $\mathrm{C}$ satellites, and airborne campaigns such as the Atmospheric Tomography Mission (AToM; Prather et al. 2018) focused on the remote atmosphere. ACT-America flights fill the observational gap left among continuous-in-time but spatially sparse, tower-based C measurements (Andrews et al. 2014), spatially extensive, but spatially and temporally sparse 
long-term aircraft profiling (Sweeney et al. 2015; Machida et al. 2008; Schuck et al. 2009), and globally extensive but temporally sparse (compared to synoptic weather) provided by low-Earth-orbit satellite systems (Kuze et al. 2016; Crisp et al. 2017). Here we present ACTAmerica's mission design, and an interpretation of the results emerging from the project.

\section{Mission goals and objectives}

The ACT-America mission's overarching goal is to enable atmospheric inversions to quantify the contemporary carbon cycle with the accuracy and precision needed: 1) to evaluate and improve terrestrial carbon cycle models, and 2) to monitor carbon fluxes in support of climate change mitigation efforts. This overarching goal is being pursued via three specific objectives: 1) quantification and reduction of uncertainty in simulations of atmospheric $C$ transport, 2) quantification and reduction in uncertainty in prior $C$ flux estimates, and 3) evaluation of the ability of the $\mathrm{OCO}-2$ instrument to capture regional-scale, tropospheric gradients in column $\mathrm{CO}_{2}\left(\mathrm{XCO}_{2}\right)$. Since the atmospheric and ecosystem processes, we study in the central and eastern United States are found throughout Earth's midlatitudes, and the satellite observations we are evaluating are global in scope, our intention is to improve our ability to diagnose Earth's carbon cycle on a global scale, and over the decades encompassed by the long-term C observing network. The intersecting elements of the mission are illustrated in Fig. 1.

\section{Instruments and platforms}

Airborne platforms. Two aircraft, a NASA Langley Research Center Beechcraft B-200 King Air, and a NASA Wallops Flight Facility Lockheed C-130 Hercules, carried a common suite of in situ, continuous sensors measuring meteorological variables (wind speed, wind direction, and atmospheric temperature, water vapor, and pressure), aircraft position, atmospheric C mole fractions (Baier et al. 2020), and atmospheric $\mathrm{C}$ tracers including carbon monoxide (CO), ozone $\left(\mathrm{O}_{3}\right)$, ethane $\left(\mathrm{C}_{2} \mathrm{H}_{6}\right.$; Weibring et al. 2020; Kostinek et al. 2019) and approximately 50 long-lived trace gases including ${ }^{14} \mathrm{CO}_{2}$ and carbonyl sulfide (OCS) using flask whole-air samplers (Baier et al. 2020). The C-130 carried additional instrumentation, including an in situ nitrous oxide $\left(\mathrm{N}_{2} \mathrm{O}\right)$ analyzer (Kostinek et al. 2019), a downward-pointing backscatter lidar able to detect clouds and clear-air atmospheric structure including atmospheric boundary layer (ABL) depth (McGill et al. 2004; Pal et al. 2020b), and a downward-pointing integrated path differential absorption (IPDA) lidar to measure either column $\mathrm{CO}_{2}\left(\mathrm{XCO}_{2}\right.$, first four flight campaigns; Campbell et al. 2020) or column $\mathrm{CH}_{4}\left(\mathrm{XCH}_{4}\right.$, aerosol/cloud, and ABL depth, final flight campaign). More details on the instruments, performance metrics, calibration procedures and data archives are found in Wei et al. (2021).

Towers. Communications towers were instrumented with Picarro cavity ring-down spectrometers to measure $C$ at approximately $100 \mathrm{~m}$ above ground (Miles et al. 2018). Eleven towers were selected to fill in gaps in the NOAA GGGRN. These towers operated throughout the years (2016-19) of the ACT-America airborne campaigns.

Satellites. Fourteen ACT-America flights were coordinated with the passage of $O C O-2$ such that the aircraft were collocated temporally and spatially within the instrument's measurement swath (Bell et al. 2020). The final ACT-America flight campaign overlapped with operations of the European Space Agency's TROPOMI instrument, which retrieves $\mathrm{XCH}_{4}$ globally on a daily basis.

\section{Ensemble modeling system}

Ensemble modeling is an essential element of ACT-America's methodology (Fig. 1). A transport ensemble consisting of a mesoscale atmospheric transport model with multiple 
- Four seasons, five campaigns

- 31 synoptic sequences

- 1140.7 flight hours

- $A B L+$ free troposphere flight legs

- $\mathrm{CO}_{2}, \mathrm{CH}_{4}, \mathrm{XGHGs}, \mathrm{ABL}$ depth, winds, temp, $\mathrm{H}_{2} \mathrm{O}, \mathrm{CO}, \mathrm{C}_{2} \mathrm{H}_{6}$, COS, ${ }^{14} \mathrm{CO}_{2}, \mathrm{~N}_{2} \mathrm{O}, \mathrm{O}_{3}$

Atmospheric transport model evaluation

Eulerian + Lagrangian Regional + Global Calibrated WRF ensemble

WRF GEOS-Chem LPDM TM5 PCTM
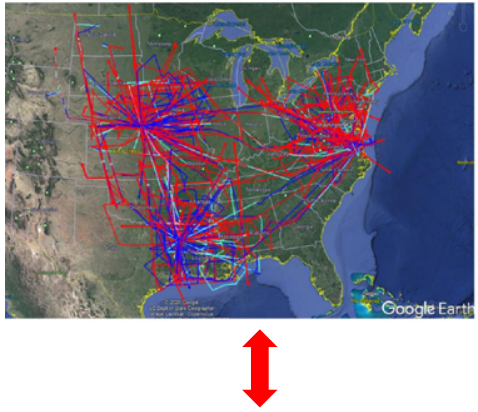

GHG flux evaluation

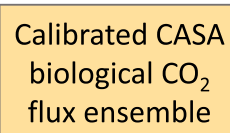

SiB4

CarbonTracker oCO2v9MIP

Methane emissions

Oil and gas

Wetlands

Agriculture
Measurements

ACT-America aircraft and towers

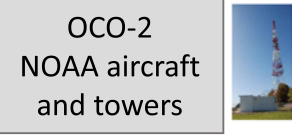

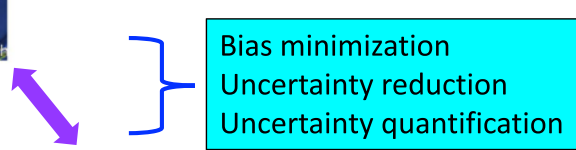

OCO- $2 \mathrm{XCO}_{2}$ evaluation $\mathrm{XCO}_{2}$

Interpolated in situ $\mathrm{CO}_{2}$ curtains

Fig. 1. ACT-America measurements complement long-term in situ and remote sensing GHG observations by providing the first detailed measurements of the GHG structure of 31 synoptic weather systems that passed through the central and eastern United States, a region of strong, seasonally varying GHG fluxes and vigorous mixing by midlatitude cyclones. The GHG and meteorological observations are complemented with ensembles of atmospheric and ecosystem models, and measurements of trace gases, that aid in disaggregating GHG sources. Improved GHG flux estimates are pursued by minimizing biases and random errors, and quantifying the remaining uncertainty in atmospheric transport simulations, GHG flux models, and OCO-2 $\mathrm{XCO}_{2}$ observations. These improved components can be incorporated into atmospheric inversion systems. ACT-America observations are also used as independent data to evaluate existing atmospheric inversion systems. The joint observations of greenhouse gases, associated trace gases, and atmospheric transport variables help to detangle the difficult issue of combined atmospheric transport and C flux biases that are present in all atmospheric inversion studies. The central image overlays all ACT-America flight tracks (C-130 in red; B-200 first sortie in dark blue, second sortie in light blue). Images show the NASA C-130 and B-200 aircraft, an instrumented communications tower, and a rendering of the $O C O-2$ satellite platform.

physical parameterizations (Díaz-Isaac et al. 2019), initial conditions (Chen et al. 2019; Feng et al. 2019a,b), and resolutions (Samaddar et al. 2021) is embedded within a suite of global atmospheric C reanalyses (Butler et al. 2020; Feng et al. 2019a,b), and can include an ensemble of ecosystem and anthropogenic C flux estimates (Zhou et al. 2020; Feng et al. 2019a,b). This multicomponent ensemble system enables model sensitivity to any of the individual components to be explored independently (e.g., Feng et al. 2019a,b; Chen et al. 2019). This enables ACT-America to address a primary challenge in the study of atmospheric C: the disaggregation of model-data errors caused by surface fluxes versus atmospheric transport.

The model ensemble provides a realistic assessment of uncertainty only if the range of variation in the components represents our uncertainty in those components. Thus, another critical feature of the ensemble modeling effort is the attempt to calibrate the ensemble versus both meteorological measurements (Díaz-Isaac et al. 2019; Feng et al. 2019a,b) and atmospheric C flux and mole fraction observations (Zhou et al. 2020; Feng et al. 2019a,b). Calibration in this case refers to adjusting the range of the model ensemble so that the members just encompass the observations for the purpose of quantifying uncertainty. Minimizing bias is also critical to the quality of the ensemble (Díaz-Isaac et al. 2019). Continued evaluation and improvement 
of the model ensembles using ACT-America observations, and applications of the ensembles to improve inversions, is a central focus of ongoing investigation.

In addition to the ensemble, we have created a single member "baseline simulation" of total atmospheric $\mathrm{CO}_{2}$ and $\mathrm{CH}_{4}$ continental enhancements spanning the entire flight campaign (Feng et al. 2020). The $\mathrm{C}$ mole fractions are broken down according to their source (e.g., boundaries, fossil, biogenic; Feng et al. 2019b; Barkley et al. 2019a). This baseline simulation has been combined with the HYSPLIT (Stein et al. 2015) and Flexible Particle (FLEXPART; Pisso et al. 2019) Lagrangian dispersion models to create influence functions for both flask samples (Baier et al. 2020) and continuous aircraft observations (Cui et al. 2021).

\section{Flight patterns and campaigns}

Flight regions. We chose ACT-America flight regions to encompass a range of weather and $\mathrm{C}$ fluxes. The Midwest region (flight base: Lincoln, Nebraska) enabled the sampling of midlatitude cyclones early in their life cycles, and agricultural C fluxes. The south-central region (flight base: Shreveport, Louisiana) featured coastal convection, strong atmospheric influence from the Gulf of Mexico, substantial anthropogenic C fluxes, and forested and agricultural ecosystems with substantially different seasonality than the other study regions. The midAtlantic region (flight bases NASA Wallops Flight Facility in Chincoteague, Virginia, and NASA Langley Research Center in Hampton, Virginia) spanned the Appalachian temperate forests, large anthropogenic $C$ fluxes, and late-stage weather systems that carried the accumulated signatures of $\mathrm{C}$ fluxes from across the continent. These central and eastern U.S. ecosystems are highly productive and encompass a large fraction of U.S. ecosystem and anthropogenic C fluxes and flux uncertainty (Alvarez et al. 2018; Feng et al. 2019b; USGCRP 2018).

Flight patterns. ACT-America conducted three types of flights: OCO-2 underflights, fairweather flights. and frontal flights. The fair-weather and frontal flights were arranged to construct synoptic sequences (Fig. 2), with flight planning guided by a vigorous daily flight forecasting effort. Both aircraft were deployed for the majority of ACT-America flights. All flights were conducted during late morning through midafternoon hours in order to minimize vertical gradients in $\mathrm{C}$ within the $\mathrm{ABL}$.

OCO-2 UnDERfLIGHTS. For OCO-2 underflights, the two aircraft flew out and back along a single track approximately $500 \mathrm{~km}$ in length that was within the sampling swath of the satellite (Fig. 3). Since OCO-2 measurement retrievals are limited in the presence of cloud fields, clear conditions were targeted. This observation strategy, designed to test the ability of OCO-2 to retrieve regional-scale spatial variability in tropospheric $\mathrm{XCO}_{2}$, represents a unique contribution (Bell et al. 2020) to the $\mathrm{OCO}-2 \mathrm{XCO}_{2}$ evaluation literature.

Synoptic Sequences. We designed the majority of ACT-America flights to sample the GHG and meteorological properties of midlatitude weather systems. This included multilevel flights across frontal boundaries, and within pre- and postfrontal fair-weather air masses. A sample multiday flight sequence from the summer of 2016 is illustrated in Fig. 4.

Prefrontal conditions in the U.S. Midwest were sampled on 9 and 10 August (Fig. 4a). The fair-weather patterns flown on these two days were designed so that the ABL portion of the 9 August flight was approximately one day's advection upwind of the ABL air sampled on 10 August to enable regional C flux estimates. Flow in the prefrontal conditions came primarily from the south, but with some northerly airmass history since the flights were close to the high pressure center (Fig. 4f). These 2-day sequences were flown primarily in the summer of 2016, and close to the center of fair-weather high pressure systems whose light winds allowed this quasi-Lagrangian flight plan to be executed. ABL C mole fractions in fair weather were 


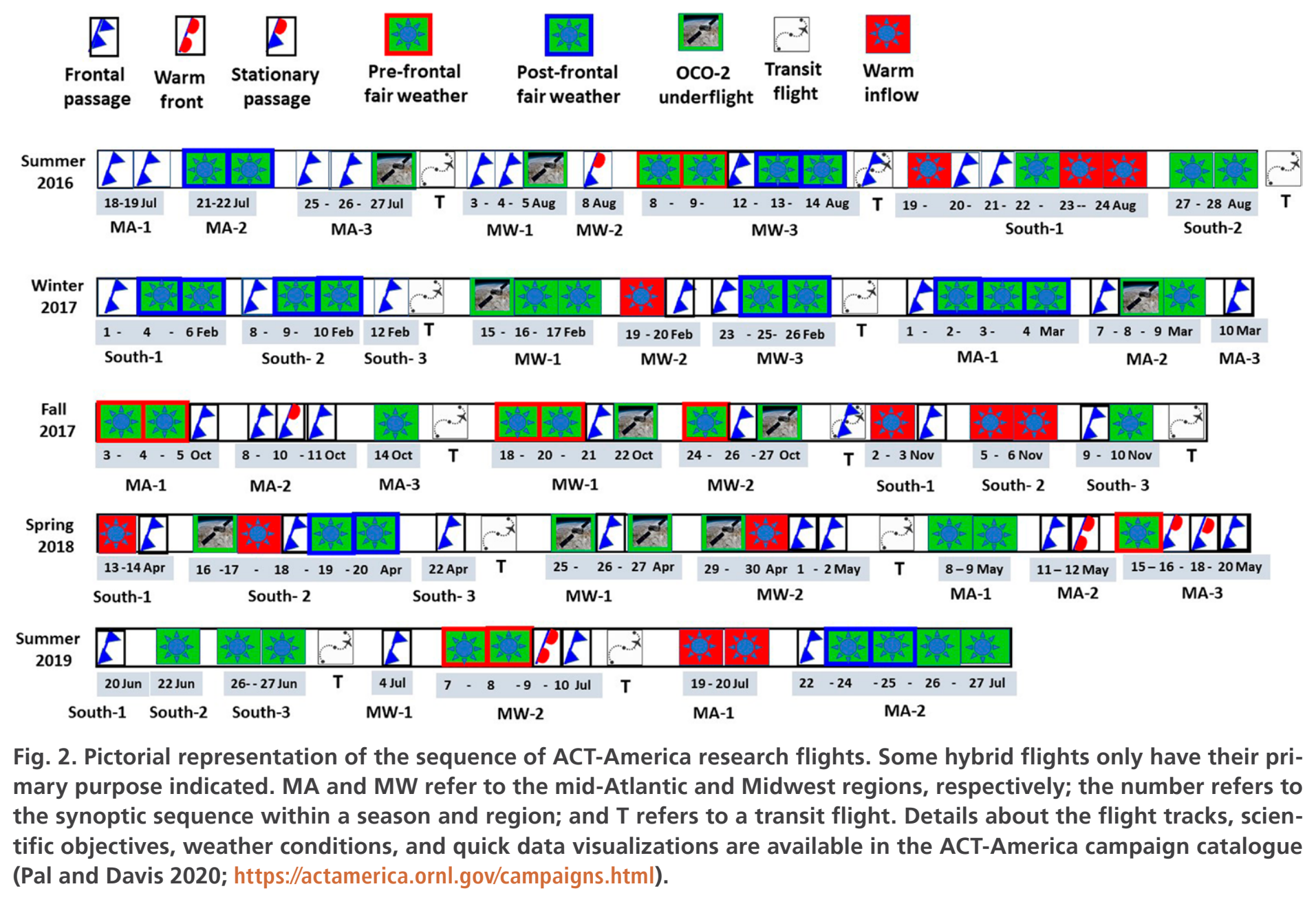

often strikingly heterogeneous (Figs. 4a,c), reflecting both spatially heterogeneous fluxes and the variable airmass history found within a high pressure center (Fig. 4f).

A front moved through the region on 12 August 2016 and was sampled at four altitudes along a flight track approximately perpendicular to the front (Fig. 4e). Large differences in both $\mathrm{CO}_{2}$ and $\mathrm{CH}_{4}$ were found across the front in both the ABL and the free troposphere (FT), with larger differences in the ABL (Fig. 4d): this was typical of the fronts sampled during this campaign (Pal et al. 2020a). The influence functions (Fig. 4g) show the convergence at the front of air masses influenced by $\mathrm{C}$ fluxes from the upper Midwest and the South. Persistent cross-frontal $\mathrm{C}$ differences were found in all seasons, but were the largest in the summer. This flight also shows an elevated band of $\mathrm{CO}_{2}$ in the ABL at about $-94^{\circ}$ to $-95^{\circ}$ longitude, just ahead of the cold front (Figs. 4b,d), a feature common to all frontal crossing flights (Pal et al. 2020a). The large and persistent cross-frontal C mole fraction differences (Pal et al. 2020a) are highly sensitive to regional C fluxes (Hu et al. 2021; Samaddar et al. 2021), and emphasize both the importance of fronts in the meridional transport of C (Schuh et al. 2019) and their value in determining regional C fluxes (Hu et al. 2021; Barkley et al. 2019a).

Postfrontal, fair-weather flights on 13 and 14 August (Fig. 4c) sampled the strong shift to northwesterly winds sensitive to fluxes from the upper Midwest (Fig. 4h). ABL C mole fractions remained highly variable (Fig. 4c), despite the homogeneous airmass history.

The slightly elevated $\mathrm{ABL} \mathrm{CO}$ in the warm sector and strongly depleted $\mathrm{CO}_{2}$ in the cold sector (Figs. $4 \mathrm{a}-\mathrm{c}$ ) suggest a weak $\mathrm{CO}_{2}$ source in southern ecosystems and a strong Midwestern ecosystem sink then (Pal et al. 2020a). The free tropospheric cross-frontal mole fraction differences reflect large-scale seasonal, latitudinal gradients (Pal et al. 2020a). This sequence also illustrates the strong organization of $\mathrm{C}$ mole fractions as a function of airmass history 

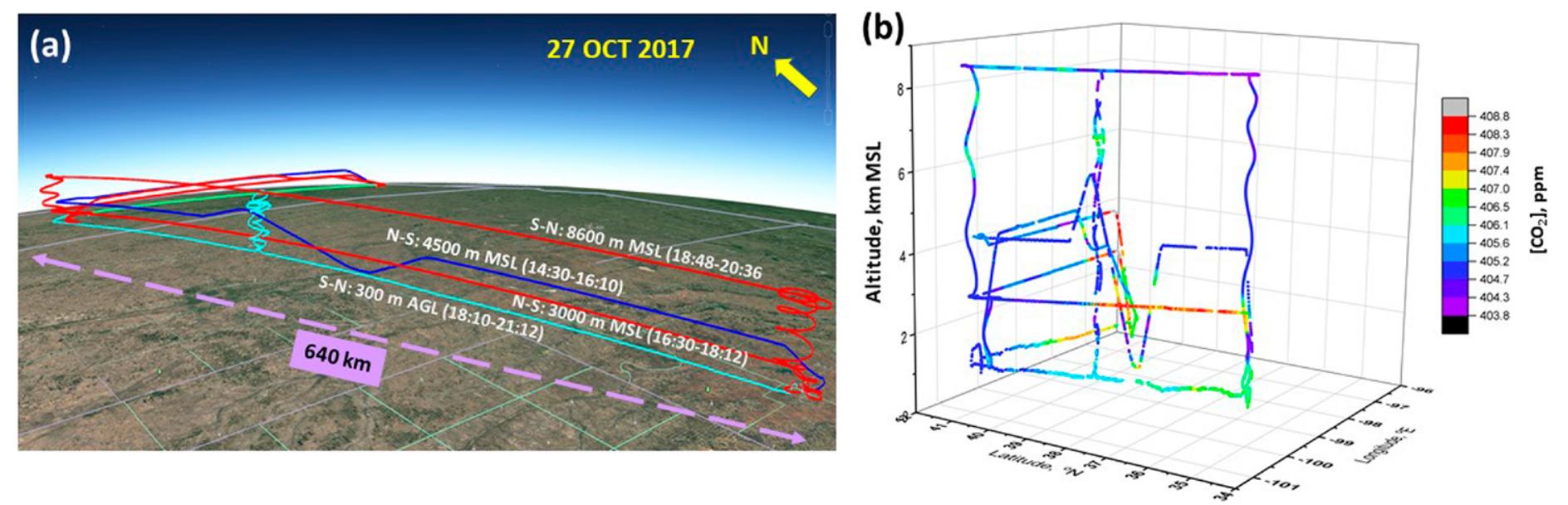

(c)
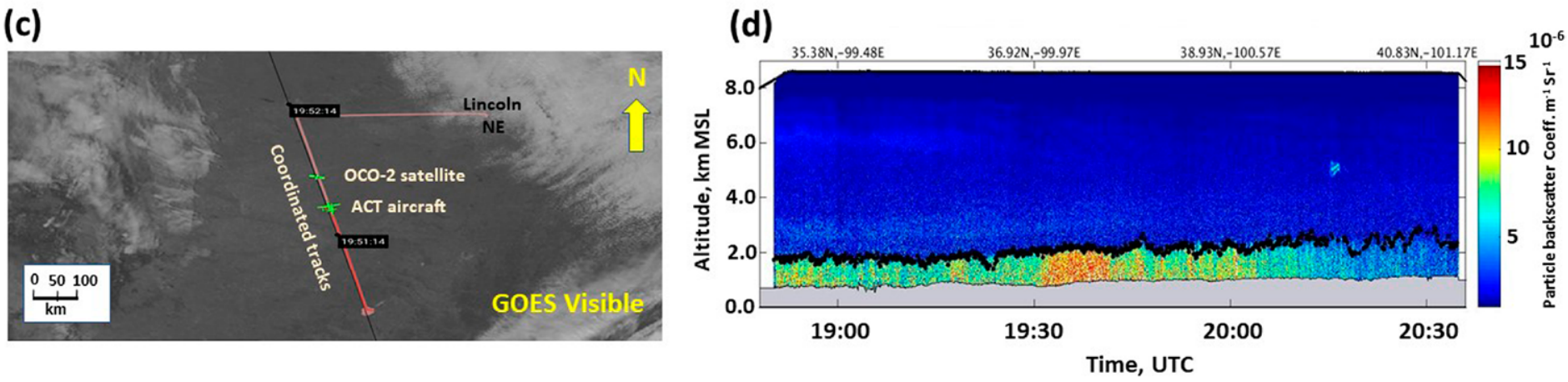

Fig. 3. OCO-2 underflight from 27 Oct 2017. (a) The aircraft flew at multiple altitudes to measure; (b) in situ $\mathrm{CO}_{2}$ along the OCO-2 sampling swath. The $\mathrm{C}-130$ flew at its maximum altitude on one pass to measure partial column $\mathrm{XCO}_{2}$ (Campbell et al. 2020) with the Multifunctional Fiber Laser Lidar (MFLL). The flight was coordinated so that (c) at the midpoint in time of the flight pattern, the C-130 was at maximum altitude directly overflying the B-200, which was performing an in situ spiral from 300 m AGL up to the altitude of the C-130 overpass, when the OCO-2 satellite overflew both aircraft and (d) the Cloud Physics Lidar (CPL) mapped-out backscatter (color scale) and a wavelet algorithm was used to retrieve ABL depth (solid black line) along the flight track.

associated with the passage of weather systems. Averaging soundings seasonally or regionally without attention to the synoptic state will erase this valuable information about upwind fluxes. Model-data comparisons sampled according to airmass history show more ability to distinguish among simulations of $\mathrm{C}$ fluxes and transport than comparisons that average all data (Gerken et al. 2021; Gaudet et al. 2021).

Gulf INFLOW FLIGHTS. In all seasons, the Gulf of Mexico provided distinct, homogeneous $\mathrm{C}$ upwind boundary conditions for our flights. This continental boundary exhibited itself most strongly in the prefrontal and warm sector data in the South and Midwest regions. Those air masses had considerably less variability than the air coming from the northwest across a large expanse of the North American continent (Gerken et al. 2021, manuscript submitted to J. Geophys. Res. Atmos.). We took advantage of this simple boundary condition by deploying a number of flights downwind of the Gulf when high pressure systems to the east led to steady onshore flow (warm inflow in the South, Fig. 2). The change in $\mathrm{C}$ mole fractions downwind of the Gulf provides another upwinddownwind constraint on regional fluxes in the far southern portion of our study domain.

FAIR-weather transects. To better capture a large swath of upwind fluxes, and because in the dormant seasons ABL wind speeds were often too high to make a 2-day Lagrangian sequence feasible, we changed our flight strategy for fair-weather conditions to single flight days with a long, crosswind transect and a second upwind transect to measure the changes in $\mathrm{C}$ mole fractions caused by more local fluxes. 


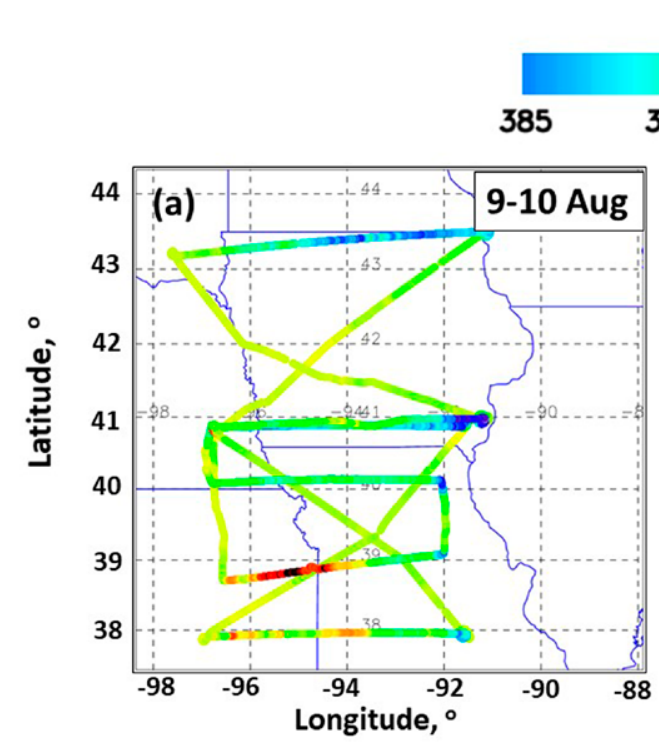

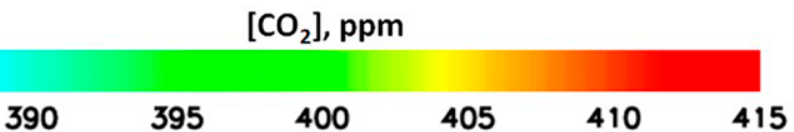
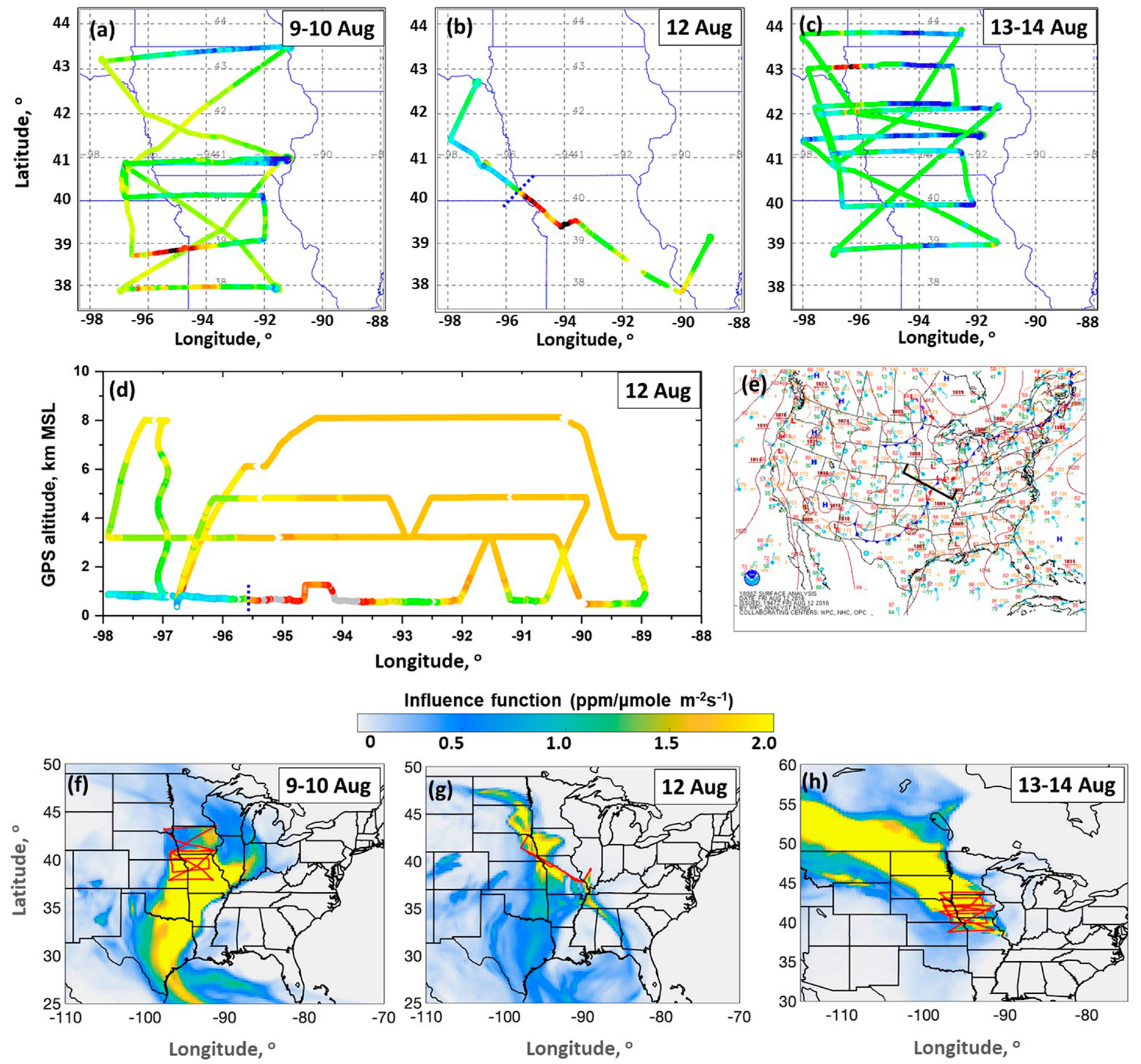

Fig. 4. Illustration of a Midwest synoptic sequence from the summer 2016 flight campaign. (a)-(c) Flight tracks for 9-14 Aug 2016 showing in situ $\mathrm{CO}_{2}$ measured along the tracks (only $\mathrm{ABL} \mathrm{CO}_{2}$ is shown on 12 Aug when multiple tracks were stacked in the vertical). Fair-weather portions include ABL (east-west legs) and lower-free-tropospheric (diagonal and north-south) flight legs arrayed in quasi-Lagrangian 2-day sequences. (d) Latitude vs altitude $\mathrm{CO}_{2}$ mole fractions during the frontal crossing on 12 Aug. The approximate surface frontal position is marked with the dotted black line. (e) The surface weather map for 1800 UTC 12 Aug (courtesy of the NOAA Weather Prediction Center, www.wpc.ncep.noaa .gov) shows synoptic conditions with the flight track position overlaid. (f)-(h) The associated upwind influence functions for the ABL portions of each flight.

LIDAR OVERPASSES. Nearly every C-130 flight included one to four lidar overpasses of a spiral ascent or descent. Some of these spirals included lidar overpasses at multiple altitudes. These 166 overpasses (a subset after screening for non-ideal conditions) enabled 
empirical tests and correction for biases in the lidar $\mathrm{XCO}_{2}$ (Campbell et al. 2020) and $\mathrm{XCH}_{4}$ observations.

FLIGHT CAMPAIGN CLIMATOLOGY. FLIGHT CAMPAIGNS SAMPLED THE LARGE SEASONALITY IN BOTH WEATHER AND ECOSYSTEM C fLUXES CHARACTERISTIC OF THE MidLATITUDES. Flight campaigns (Fig. 2) were long enough to capture seasonally typical flux and weather conditions in each of our three flight regions. Flights were conducted for 2 weeks in each region, sampling roughly two synoptic sequences per region, and targeted typical rather than extreme conditions. Two summer flight campaigns were conducted both to increase sampling when biogenic $\mathrm{CO}_{2}$ fluxes are at their peak and, for the southern and midwestern regions, to capture earlier and later summer conditions.

Summer 2016 sampled mid- to late-summer conditions. Climatological conditions were fairly typical in two of our three flight regions. One significant exception was the flooding that occurred in the South, with the most extreme flooding taking place in southern Louisiana (Brown et al. 2020). Our final flight campaign, summer 2019, was conducted in early- to midsummer conditions and was intended to sample earlier-season biogenic $\mathrm{CO}_{2}$ fluxes a full 2 months earlier than our summer 2016 campaign in the South, and 1 month earlier in the Midwest. This plan was complicated by extreme flooding in the late spring of 2019 in the central United States (Yin et al. 2020). The flooding delayed planting of crops in the Midwest by more than 2 weeks, and the landscape in early July appeared to be roughly a month behind in crop development. The South was not as broadly impacted in terms of vegetation phenology, though river valleys were flooded all across the region. The mid-Atlantic region was sampled at the same time of year in both campaigns. Summer 2019 in the mid-Atlantic included a period of extreme heat (17-22 July).

Other seasonal campaigns also included climatological anomalies worthy of mention. The midwestern portion of the winter 2017 flight campaign encountered anomalously warm conditions from 13 to 18 February, approximately the first week of flights. The regional surface remained snow-covered and the warm air and snow-covered surface resulted in very shallow boundary layers until a strong storm system on 20 February, the center point of one of the synoptic sequences sampled by ACT (Fig. 2), brought a return to more typical regional weather conditions. The mid-Atlantic winter campaign (27 February-10 March) coincided with an early spring. Snowmelt had already occurred over most of the region. Exposed soils and lack of any significant transpiration from vegetation led to high sensible heat fluxes and some very deep ABLs (1-10 March), as is typical of the period between snowmelt and green-up in this region.

The fall 2017 campaign was climatologically typical across all regions. The southern region retained some leaf cover and photosynthetic activity, while the other regions were mostly senescent. Atmospheric boundary layers were well defined, and we encountered a number of relatively clear, dry frontal passages. One notable weather event was the passage through our study region of Hurricane Nate on 8-10 October. We did not deploy research flights to study the hurricane, choosing to sample the more common midlatitude cyclones, but mid-Atlantic region flights did take place before and after the hurricane passage.

The spring 2018 campaign followed an unusually snowy winter and late greening in the Midwest. Flights over the Midwest included some snow-covered terrain, and no appreciable photosynthetic activity. Flights in southern and mid-Atlantic regions spanned the boundary of the vegetation greening. The greening was quite evident in the atmospheric data, with readily observed changes in $\mathrm{ABL} \mathrm{CO}$ that were correlated with the boundary of vegetation greenness (Fig. 5). The other notable weather condition for the campaign was the presence of two stationary fronts, one that extended from the Gulf to the upper Midwest and persisted over this region from 30 April through 3 May. We sampled the stationary front three times 

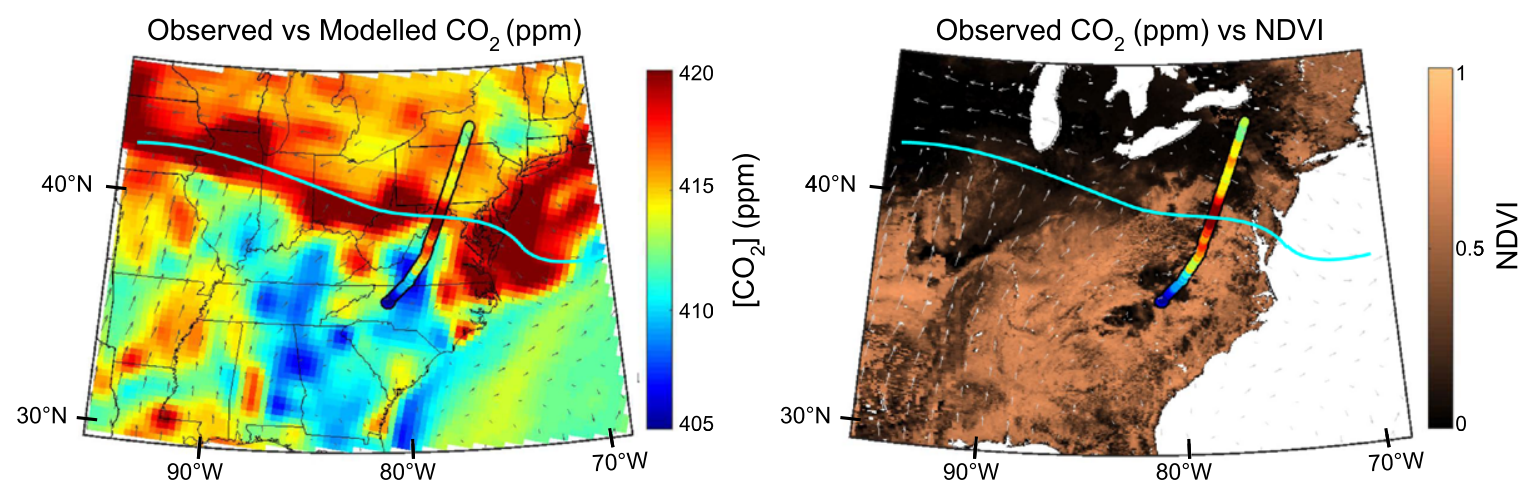

Fig. 5. (left) Observed vs simulated $A B L C_{2}$ for the flight of 11 May 2018. Simulated $\mathrm{CO}_{2}$ mole fractions and wind barbs are plotted at $500 \mathrm{~m}$ AGL at 1800 UT; flight altitude was roughly $300 \mathrm{~m}$ AGL and took place between 1600 and 1900 UT. The simulation is from the ACT-America WRF baseline run, with CarbonTracker surface fluxes and lateral boundary conditions (Feng et al. 2020). (right) Observed $\mathrm{ABL} \mathrm{CO}_{2}$ mole fraction and normalized difference vegetation index (NDVI) during the day of the flight (Vermote 2019). The teal line marks the approximate location of a stationary front that was present at that time.

from our midwestern flight base (Fig. 2). The other stationary front was west to east in orientation, and persisted over the mid-Atlantic region from 11 to 18 May. Five flights sampled this front. These multiday case studies are ripe for case studies, including strong biological flux contrasts and active atmospheric mixing.

\section{Analyses}

Carbon weather observational metrics. Denning et al. (1995), Stephens et al. (2007), Pickett-Heaps et al. (2011), and Thompson et al. (2016) have all illustrated the value of evaluating atmospheric inversion systems using vertical $\mathrm{C}$ profiles. Inspired by this past work, and following the working hypothesis that accurate understanding of $\mathrm{C}$ mole fractions within midlatitude weather systems is essential for accurate atmospheric inversions, we have developed new metrics focusing on the synoptic-scale performance of atmospheric $\mathrm{C}$ simulation and inversion systems.

Pal et al. (2020a) demonstrated a set of metrics that quantify cross-frontal C mole fraction differences as a function of tropospheric layer (ABL, lower FT, upper FT), and vertical differences in $\mathrm{C}$ mole fractions between these layers within the cold (postfrontal) and warm (prefrontal) air masses. Pal et al. (2020a) show that these metrics are highly consistent within a season across the entire central and eastern United States. Gerken et al. (2021, manuscript submitted to J. Geophys. Res. Atmos.) expanded this approach to include probability distributions and spatial variograms of model-data differences in $\mathrm{CO}_{2}$ mole fractions within these atmospheric sectors. Gerken et al. (2021, manuscript submitted to J. Geophys. Res. Atmos.) illustrate that, when averaged across season, region altitude and air mass, model-data comparisons of $\mathrm{CO}_{2}$ may show relatively little bias, but that when data are disaggregated by altitude and air mass, systematic biases appear.

We have included diagnostic flags in the ACT-America in situ observations to enable analyses that are oriented with respect to these synoptic metrics (Davis et al. 2018). All in situ aircraft data were complemented with three flags that identify whether or not the observations are within the ABL, the airmass position of the data point (warm/prefrontal, cold/postfrontal, or ambiguous), and the aircraft maneuver (level leg, takeoff, landing, spiral ascent/descent, en route ascent/descent). Flags exist for every ACT-America in situ data point and these are integrated into the flight data stored at the Oak Ridge DAAC (Wei et al. 2021; Davis et al. 2018) and as an additional download accompanying NOAA's ObsPack product (Schuldt et al. 2020). 
0CO-2 tropospheric XCO2 variability. Multiple OCO-2 underflights were evaluated by Bell et al. (2020). Spatial gradients in tropospheric $\mathrm{XCO}_{2}$ across the few- to several-hundred-kilometer flight paths differed by $0.1 \mathrm{ppm}(100 \mathrm{~km})^{-1}$ or less among three $\mathrm{XCO}_{2}$ estimates $(0 C O-2$, airborne lidar and in situ airborne $\mathrm{CO}_{2}$ assimilated into a $\mathrm{C}$ and weather reanalysis system). These results suggest that regional structures in $\mathrm{OCO}-2 \mathrm{XCO}_{2}$ can be used to inform regional-scale flux inversions, and are motivating both direct observational analysis of synoptic-scale variations in $\mathrm{XCO}_{2}$ (Wang et al. 2021, manuscript submitted to J. Geophys. Res. Atmos.), and new descriptions of $\mathrm{OCO}-2 \mathrm{XCO}_{2}$ uncertainty structure in atmospheric inversions (Baker et al. 2021, manuscript submitted to Geosci. Model Dev. Discuss.). Higher resolution inversion systems may be needed to take full advantage of this information.

Seasonal, regional flux evaluation. ACT-America flight data are being used to evaluate $\mathrm{C}$ fluxes in two ways. First, multiple C flux estimates, including ACT-America's Carnegie Ames Stanford Approach (CASA)-based $\mathrm{CO}_{2}$ flux ensemble (Zhou et al. 2020), have been propagated forward in our baseline WRF simulation. These simulated atmospheric $C$ mole fractions can be compared to ACT-America airborne data to identify the most plausible ensemble members (e.g., Feng et al. 2021). Case studies exploring realizations of the Vegetation Photosynthesis and Respiration Model (VPRM) have also been performed (Hu et al. 2021). Flux estimates can also be adjusted to maximize the fit to the ACT-America observations (e.g., Barkley et al. 2019a,b). Second, back-trajectory Lagrangian influence functions (Cui et al. 2021) created with the WRF baseline simulation can be convolved with flux estimates to estimate atmospheric $\mathrm{C}$ at the locations of aircraft observations. These model-data differences can be used to evaluate regional, seasonal flux estimates, including terrestrial biosphere models (Parazoo et al. 2021) and posterior fluxes from atmospheric inversions (Cui et al. 2021). The influence functions enable any flux estimates to be evaluated without requiring them to be coupled to a new atmospheric transport simulation.

Boundary conditions. These $\mathrm{C}$ flux evaluations require treatment of $\mathrm{C}$ transport from outside the region of interest. Atmospheric $\mathrm{C}$ mole fractions within our study domain can be expressed, following Feng et al. (2019b), as

$$
C_{\mathrm{tot}}=C_{b}+\sum_{i} C_{i}
$$

where $C_{\text {tot }}$ is the total atmospheric mole fraction, $C_{b}$ is the mole fraction transported from outside of the study region, and $C_{i}$ are the mole fraction contributions from sources or sinks $i$ within the study region. ACT-America has developed two independent approaches to determining $C_{b}$ so that aircraft or tower observations can be used to study continental fluxes. First, we have merged boundary conditions from global C inversion systems into our continental-scale WRF simulation domain (Butler et al. 2020). We have included multiple versions of global boundary conditions to account for uncertainty in these background conditions (Feng et al. 2019b). Background conditions account for most of the $C$ in the atmosphere of North America, but comparison of global inversion systems shows that the uncertainty in these boundary conditions is modest, typically of order $1 \mathrm{ppm}$ for $\mathrm{CO}_{2}$, compared to continental fluxes that account for several to tens of parts per million of $\mathrm{CO}_{2}$ for continental fluxes (Feng et al. 2019a,b; Chen et al. 2019). A second approach is to assume that inflow from outside of the continent is homogeneous in the vertical, and that deep vertical mixing over the continent is limited so that upper free tropospheric mole fraction measurements are approximately equal to continental background conditions (Parazoo et al. 2021). NOAA aircraft profiling on the Pacific and Gulf coasts (Sweeney et al. 2015), ACT-America profiles over the Gulf (e.g., Campbell et al. 2020) and model-data comparisons in the upper free 
troposphere (Gerken et al. 2021, manuscript submitted to J. Geophys. Res. Atmos.) suggest that this is a reasonable approximation. Comparison of these approaches and more extensive quantification of this source of uncertainty is worthwhile.

A third background scenario emerges in the attempt to isolate regional to local, not continental-scale, fluxes. In this case, free-tropospheric mole fractions are not a suitable background condition (Turnbull et al. 2015). Instead ABL mole fractions outside of the influence of the region of interest are matched with simulations of both background mole fractions and fluxes from outside the region of interest to isolate mole fraction enhancements from the region of interest (Barkley et al. 2017). This approach is difficult to apply to biogenic $\mathrm{CO}_{2}$ fluxes, since they are so broadly distributed, but this method works well for studying emissions from discrete source regions such as cities or anthropogenic $\mathrm{CH}_{4}$ emissions (Barkley et al. 2019a, 2021) and agricultural $\mathrm{N}_{2} \mathrm{O}$ emissions (Eckl et al. 2021).

Quantifying regional, seasonal fluxes also benefits from the ability to segregate component fluxes. We can do this with both numerical and observational approaches. Our WRF simulations include $\mathrm{C}$ mole fractions for each source or sink sector, making it possible to segregate, for example, atmospheric $\mathrm{CO}_{2}$ mole fractions originating from continental fossil fuel versus biogenic $\mathrm{CO}_{2}$ fluxes (Feng et al. 2019a,b; Hu et al. 2021; Samaddar et al. 2021), and atmospheric $\mathrm{CH}_{4}$ mole fractions originating from continental or regional oil and gas versus coal versus agricultural emissions (Barkley et al. 2019a,b). If the uncertainty in one particular source is known with more confidence, simulated sector mole fractions $\mathrm{C}_{\mathrm{i}}$ can be subtracted from the observed total mole fraction $\mathrm{C}_{\text {tot }}$ to isolate the sector mole fraction of interest. Calibrated ensembles (Feng et al. 2019b) can be used to address uncertainty in the sectoral fluxes.

As a complement to these numerical methods, we measured $\mathrm{CO}$ and ${ }^{14} \mathrm{CO}_{2}$ to isolate fossil fuel $\mathrm{CO}_{2}$ mole fractions (Baier et al. 2020), OCS to segregate photosynthetic versus respiratory biogenic $\mathrm{CO}_{2}$ fluxes (Parazoo et al. 2021), and ethane $\left(\mathrm{C}_{2} \mathrm{H}_{6}\right)$ to segregate thermogenic from biogenic $\mathrm{CH}_{4}$ sources (Barkley et al. 2019a,b, 2021). Figure 6 shows an example of such an analysis applied to estimating regional $\mathrm{CH}_{4}$ emissions from the southern United States.

ACT's lidar-based column $\mathrm{C}$ measurements have a unique potential to constrain regional $\mathrm{C}$ fluxes that has yet to be demonstrated. These observations, combined with backscatter lidar ABL depth measurements, can be used to infer regional GHG fluxes without concerns about the ability of in situ aircraft data to properly capture the vertical distribution of GHGs within the ABL.

Evaluation of atmospheric inversions. Disaggregating the influence of flux and transport on a given atmospheric $\mathrm{C}$ mole fraction measurement has been a challenge for atmospheric inversions for decades. ACT-America's observation of the structures of $\mathrm{C}$ mole fractions within weather systems provides a strong basis for untangling the interdependency of midlatitude weather and fluxes.

Multiple avenues of inversion system evaluation are being explored. Evaluation of atmospheric transport variables, atmospheric C mole fractions (Gaudet et al. 2021), and posterior fluxes (Cui et al. 2021) from the global-scale OCO-2 Model Intercomparison Project (OCO2 MIP; Crowell et al. 2019) is underway in an attempt to identify the inversion systems that are most consistent with ACT-America's carbon weather metrics. The same metrics will be used to evaluate continental atmospheric inversions, such as CarbonTracker-Lagrange (Hu et al. 2019), once these become available. Model studies that control for sources of variability among inversions are also underway in an attempt to identify the causes of model-data discrepancies. Studies of this sort include studies of the impact of model resolution (Samaddar et al. 2021) and atmospheric transport model (Gerken et al. 2021, manuscript submitted to J. Geophys. Res. Atmos.), both using common fluxes to isolate the impact of transport on $\mathrm{CO}_{2}$ mole fractions. More controlled model experiments confronted with ACT-America observations are needed 
to close our understanding of midlatitude $\mathrm{C}$ weather and the impact of the simulation of $\mathrm{C}$ weather on $\mathrm{C}$ flux inversions.

The ensemble modeling initiated by ACT-America (Chen et al. 2019; Feng et al. 2019a,b; 2021, manuscript submitted to Global Biogeochem. Cycles) illustrates another path to improving atmospheric inversions. Figure 7 shows the variability in $\mathrm{ABL} \mathrm{CO}_{2}$ mole fractions produced by elements of a calibrated C model ensemble (Feng et al. 2019b). Ensembles like these, if calibrated and verified with intensive regional observations like ACT-America flights, can identify those regions and times where flux uncertainty is large and other sources of uncertainty are small, and direct atmospheric inversion systems to use those data preferentially to solve for regional $\mathrm{C}$ fluxes.

Improvement of atmospheric $\mathbf{C}$ inversions. In addition to evaluating existing atmospheric inversion systems using the aircraft data as independent observations, we have begun to translate our results into improvements in regional and global atmospheric inversions. Avenues for improvement of the inversion systems include modifying the assumptions about local to regional-scale errors and error correlations in OCO-2 observations (Baker et al. 2021,
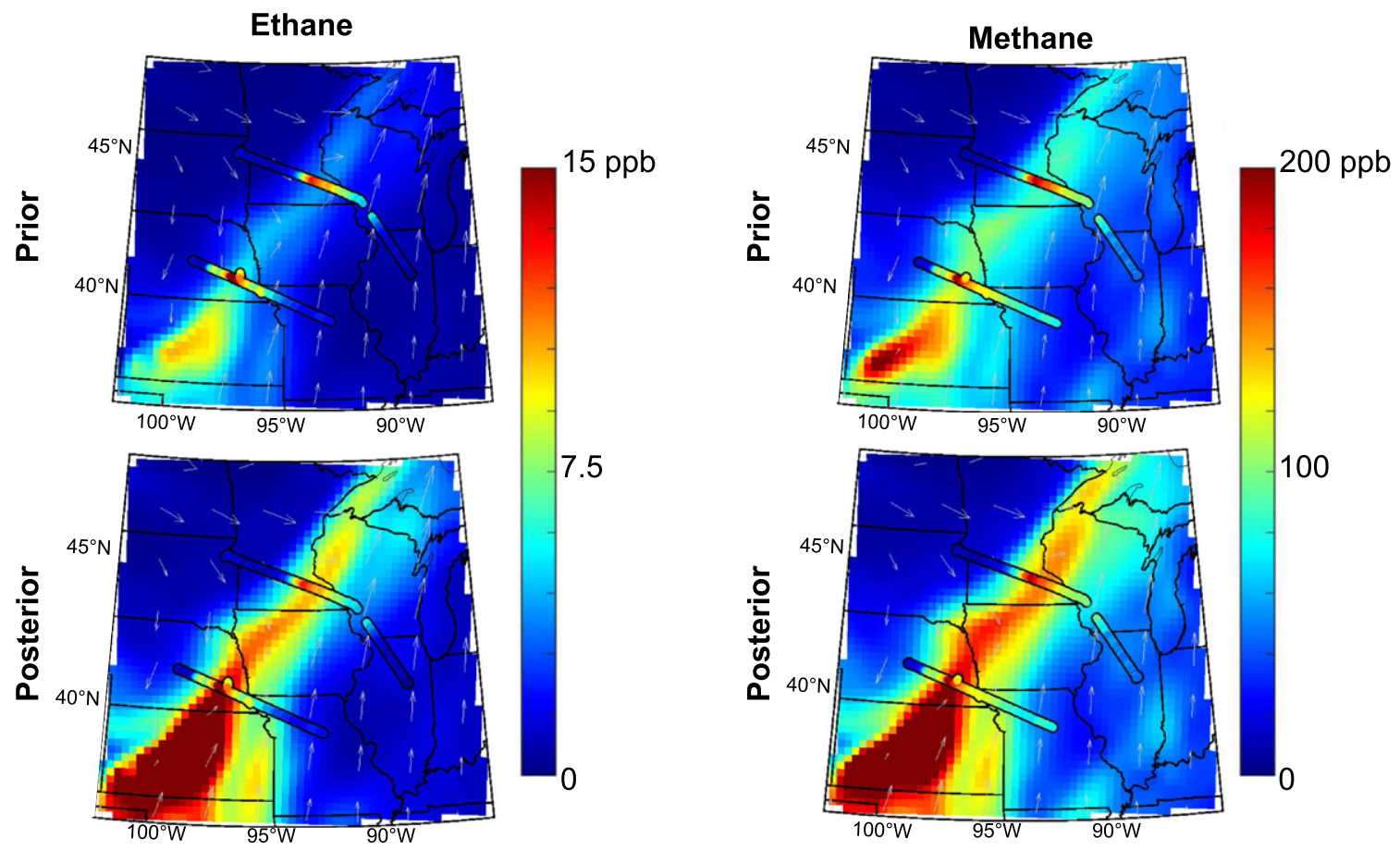

Fig. 6. Example of a dual-tracer optimization used to solve for methane emissions on 18 Oct 2017. (top left) Observed vs simulated $A B L$ ethane mole fraction enhancements relative to a background based on oil and gas sources from the EPA 2012 Gridded Methane Inventory (Massaakers et al. 2016) and an assumed average ethane/methane gas composition of 0.10 (a reasonable overall estimate for U.S. oil and gas production). (bottom left) Observed vs simulated $A B L$ ethane enhancements achieved by multiplying oil and gas emissions by a factor of 2.5. (top right) Observed vs simulated ABL methane enhancements based on the same inventory. (bottom right) Observed vs simulated ABL methane enhancements achieved by multiplying oil and gas emissions by a factor of 2.5. In all panels, simulated mole fractions (Feng et al. 2020) are from $500 \mathrm{~m}$ AGL at 1900 UT. Aircraft observations are from approximately $300 \mathrm{~m}$ AGL and were collected between 1700 and 2100 UT. A surface cold front parallels the northwest portion of the region of enhanced methane and ethane. The enhanced mole fractions are in the warm sector flowing to the north and east. The ethane observations enable source disaggregation (animal agriculture vs oil and gas production) using the ethane/methane emissions ratios. Methods follow Barkley et al. (2019a). 
(a)

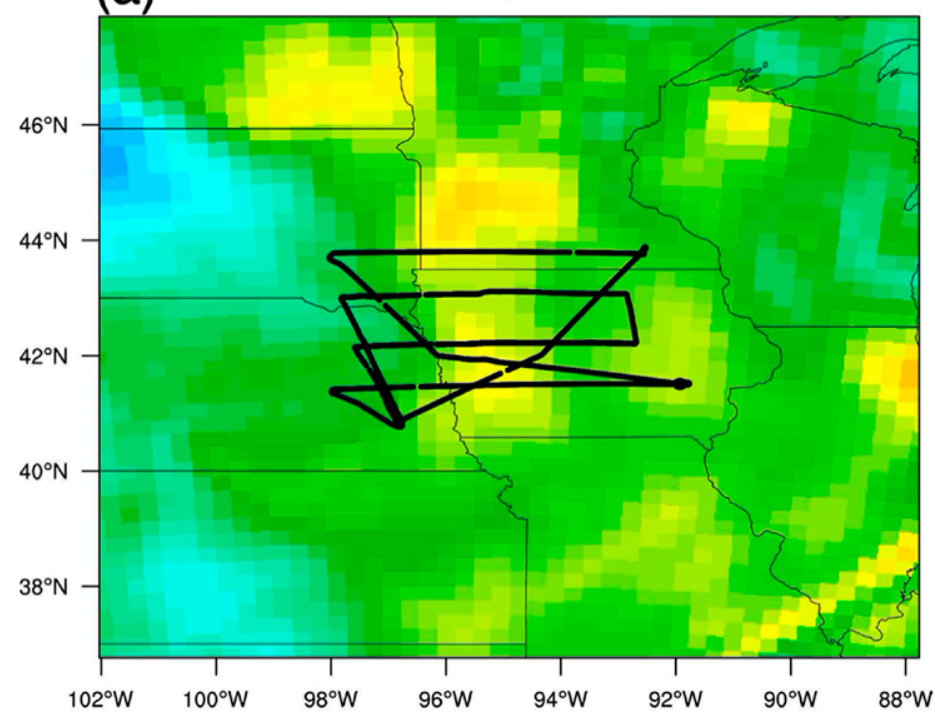

(c)

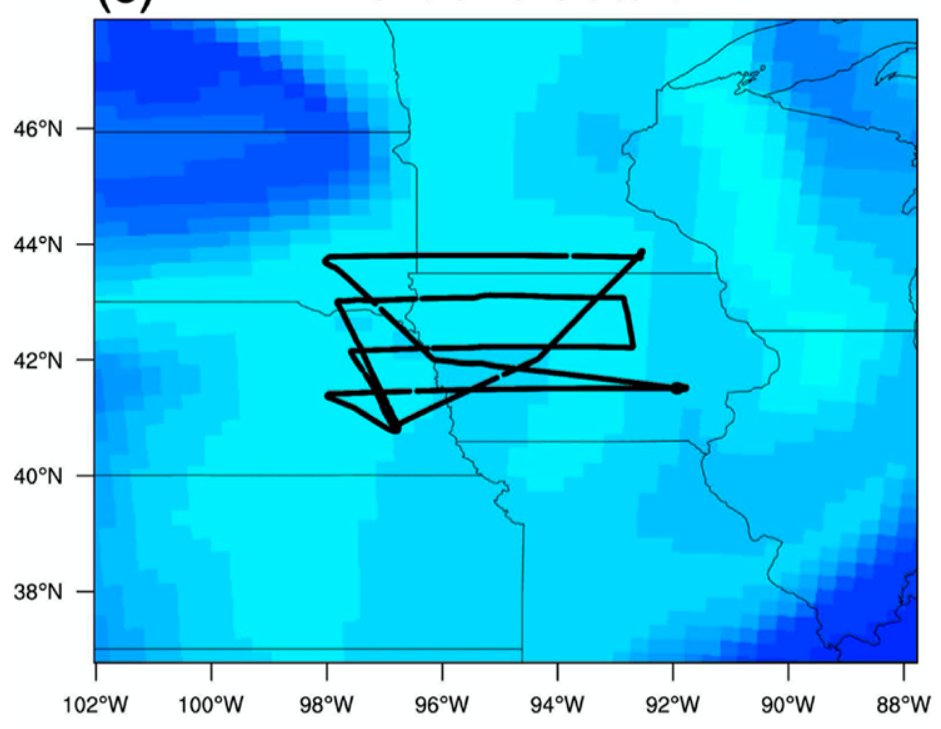

(b) RMSD over Transport 2016-08-13

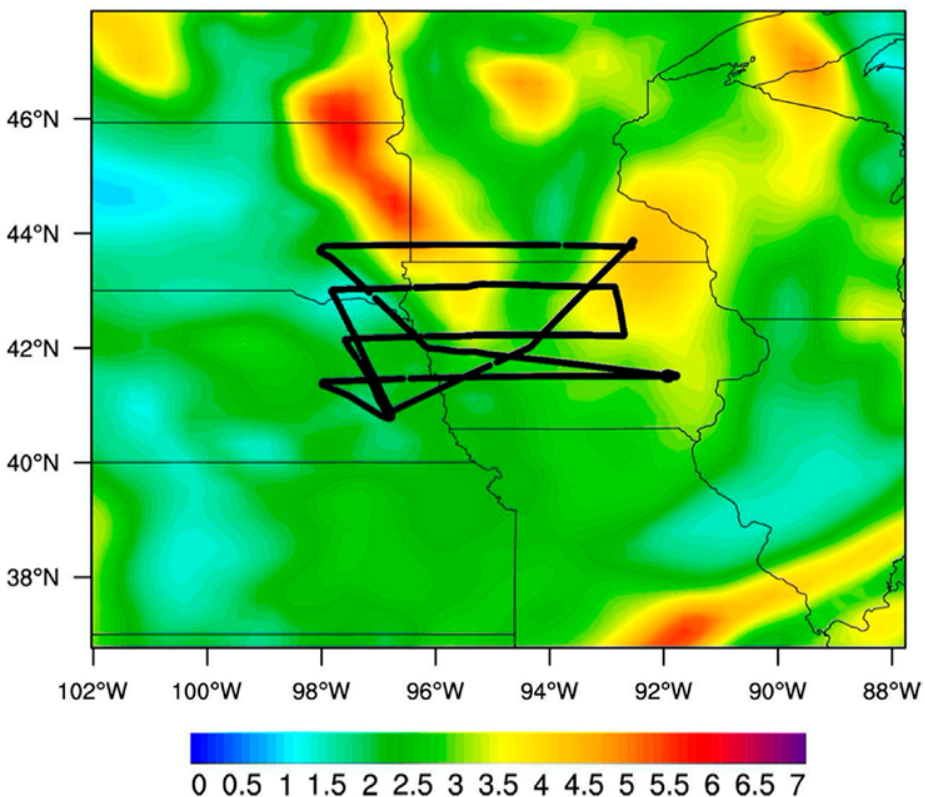

Fig. 7. Root-mean-square deviation in ABL CO2 mole fractions ( $500 \mathrm{~m} \mathrm{AGL}$ ) across components of the multicomponent ensemble simulation system described by Feng et al. (2021) at 1900 UT 13 Aug 2016, one of the fair-weather flight days shown in Fig. 4, including (a) RMSD across the CASA biological flux ensemble members, (b) RMSD across the atmospheric transport ensemble members, and (c) RMSD across the continental boundary condition ensemble members. In each case, all other components of the ensemble are held constant. The black lines show the aircraft flight patterns on this day. Feng et al. (2019b) demonstrated the calibration of this multicomponent ensemble, but with a different biological $\mathrm{CO}_{2}$ flux ensemble. The CASA ensemble may underestimate the true flux uncertainty (Feng et al. 2021).

00.511 .522 .533 .544 .555 .566 .57

manuscript submitted to Geosci. Model Dev. Discuss.), minimizing biases and adjusting uncertainties in prior fluxes used in inversions based on evaluation of these flux models (e.g., Barkley et al. 2019a, 2021; Feng et al. 2021, manuscript submitted to Global Biogeochem. Cycles), and improving atmospheric transport field and transport uncertainty assessments (Gerken et al. 2021, manuscript submitted to J. Geophys. Res. Atmos.; Feng et al. 2019a; Lauvaux et al. 2019). These advances have yet to be tested in established inversion systems. ACT-America has also begun to develop new inversion systems that can incorporate prior flux (Wesloh et al. 2020) and atmospheric transport (Lauvaux et al. 2019) ensemble information.

\section{Conclusions}

ACT-America's observational record provides unparalleled insight into the $\mathrm{C}$ fluxes and mole fractions of midlatitude weather systems-the carbon weather of the midlatitudes. We have confirmed that midlatitude weather systems are clearly responsible for a large component of the spatial and temporal variability in atmospheric $\mathrm{C}$ mole fractions over the continents, and 
have shown the strong connection between this weather-scale variability and terrestrial $\mathrm{C}$ fluxes. Modeling and analysis systems that can properly resolve these weather systems and interpret these carbon weather signals will provide superior regional and continental $\mathrm{C}$ flux estimates. Analyses that neglect the role of weather systems in C transport run the risk of masking compensating errors that will bias their results.

More work is needed to untangle the mixed influences of $\mathrm{C}$ flux and transport uncertainties at subcontinental scales in current atmospheric inversion systems. ACT-America investigations have pioneered new approaches in ensemble $C$ simulations which, combined with ACT-America's airborne database, are beginning to isolate and quantify the impact of flux versus transport errors. These methods, as they are adopted in atmospheric inversions, should continue to improve the accuracy and precision of regional inverse flux estimates.

We have demonstrated that column remote sensing technologies, both space- and airborne, have the precision and stability needed to document regional-scale atmospheric $\mathrm{C}$ gradients. These findings show promise for continued use of both passive and active remote sensing in the study of $\mathrm{C}$ mole fractions and fluxes.

An unparalleled airborne methane and ethane dataset enabled us to make strong progress in evaluating anthropogenic emissions of $\mathrm{CH}_{4}$ from the central and eastern United States. We have begun to use the airborne dataset to evaluate and improve seasonal and regional terrestrial biosphere model $\mathrm{CO}_{2}$ flux estimates. Much more can be done in this area.

Independent, routine, atmospheric evaluation of models and inventories of $\mathrm{C}$ fluxes at spatial domains of geopolitical and ecological relevance remains an important need for climate science and climate change mitigation. This is rapidly becoming feasible for fossil fuel $\mathrm{CO}_{2}$ emissions and some anthropogenic $\mathrm{CH}_{4}$ emissions. This is more challenging for broadly distributed fluxes such as agricultural and wetland $\mathrm{CH}_{4}$ emissions, and biogenic $\mathrm{CO}_{2}$ fluxes. ACT-America investigations have provided an observation and methodological framework that will enable this advance.

Acknowledgments. The ACT-America project is a NASA Earth Venture Suborbital 2 project funded by NASA's Earth Science Division. Authors were supported by the following NASA grants: NNX15AG76G to Penn State (Davis); NNX15AJ06G (Baier, Sweeney) and NNX15AW47G (Fried) to University of Colorado Boulder; NNX16AN17G to Clark University (Williams); NNL15AQ00B to Exelis (Dobler); 80NSSC19K0730 to Texas Tech and a Texas Tech University start-up research grant (Pal); NNX15AI97G (O’Dell), NNX15AJ07G (D. Baker, Schuh), NNX15AJ09G (Denning), and 80NSSC20K0924 (I. Baker) to Colorado State University; NNX17AG11G (Xue) to the University of Oklahoma. Additional support for research was provided by NASA Grants NNX12AP90G (Davis), NNX14AJ17G (Davis), NNX14AL32H (Normile), and NNX13AP34G (Lauvaux). Complementary support for tower-based measurements was provided by NASA Grant NNX14AJ17G and NIST Grant 70NANB15H336. The ORNL DAAC is sponsored by the National Aeronautics and Space Administration under Interagency Agreement 80GSFC19T0039. ORNL participation in ACT-America was funded by Interagency Agreement NNL15AA10I. NASA coauthors were supported by NASA Science Mission Directorate funding awarded in response to the Earth Venture Suborbital-2 Announcement of Opportunity NNH13ZDA001N-EVS2. Roiger was supported by DLR VO-R via the young investigator research group “Greenhouse Gases.” T. Lauvaux was supported by the French research program Make Our Planet Great Again (Project CIUDAD). Part of the research was carried out at the Jet Propulsion Laboratory, California Institute of Technology, under a contract with the National Aeronautics and Space Administration (80NM0018D0004).

The authors acknowledge NASA's Earth System Science Pathfinder Program Office, NASA's Airborne Sciences Program, NASA's Atmospheric Science Data Center, and NASA's Pleiades supercomputing facilities, as well as the administrative and flight forecasting support from Penn State's Department of Meteorology and Atmospheric Sciences. The project would not have been possible without the dedicated and tireless support of the many employees of these institutions and facilities. 
Data availability statement. ACT-America observational and modeling datasets are archived at the ORNL DAAC (https://daac.ornl.gov/actamerica) and are open to use by any investigator without restriction. $\mathrm{CO} 2$ and CH4 observations are also available through NOAA's ObsPack (Masarie et al. 2014) dataset (www.esrl.noaa.gov/gmd/ccgg/obspack/). Numerical modeling products not yet available at the ORNL DAAC are available through Penn State Data Commons.

\section{References}

Agustí-Panareda, A., and Coauthors, 2019: Modelling $\mathrm{CO}_{2}$ weather-Why horizontal resolution matters. Atmos. Chem. Phys., 19, 7347-7376, https://doi.org/10.5194/ acp-19-7347-2019.

Alvarez, R. A., and Coauthors, 2018: Assessment of methane emissions from the U.S. oil and gas supply chain. Science, 361, 186-188, https://doi.org/10.1126/ science.aar7204.

Andrews, A. E., and Coauthors, 2014: $\mathrm{CO}_{2}, \mathrm{CO}$, and $\mathrm{CH}_{4}$ measurements from tall towers in the NOAA Earth System Research Laboratory's Global Greenhouse Gas Reference Network: Instrumentation, uncertainty analysis, and recommendations for future high-accuracy greenhouse gas monitoring efforts. Atmos. Meas. Tech., 7, 647-687, https://doi.org/10.5194/amt-7-647-2014.
Baier, B. C., and Coauthors, 2020: Multi-species assessment of factors influencing regional and $\mathrm{CH} 4$ enhancements during the wintertime ACTAmerica campaign. J. Geophys. Res. Atmos., 125, e2019JD031339, https:// doi.org/10.1029/2019JD031339.

Baker, D. F., S. C. Doney, and D. S. Schimel, 2006a: Variational data assimilation for atmospheric. Tellus, 58B, 359-365, https://doi.org/10.1111/j.16000889.2006.00218.x.

- and Coauthors, 2006b: TransCom 3 inversion intercomparison: Impact of transport model errors on the interannual variability of regional $\mathrm{CO}_{2}$ fluxes, 1988-2003. Global Biogeochem. Cycles, 20, GB1002, https://doi. org/10.1029/2004GB002439. 
- H. Bösch, S. C. Doney, D. O'Brien, and D. S. Schimel, 2010: Carbon source/ sink information provided by column $\mathrm{CO}_{2}$ measurements from the Orbiting Carbon Observatory. Atmos. Chem. Phys., 10, 4145-4165, https://doi. org/10.5194/acp-10-4145-2010.

_ E. Bell, K. J. Davis, J. F. Campbell, B. Lin, and J. Dobler, 2021: A new exponentially decaying error correlation model for assimilating OCO-2 column-average $\mathrm{CO}_{2}$ data, using a length scale computed from airborne lidar measurements. Geosci. Model Dev. Discuss., https://doi.org/10.5194/gmd-2020-444, submitted.

Barkley, Z. R., and Coauthors, 2017: Quantifying methane emissions from natural gas production in north-eastern Pennsylvania. Atmos. Chem. Phys., 17, 13941-13966, https://doi.org/10.5194/acp-17-13941-2017.

_ K. J. Davis, S. Feng, N. Balashov, A. Fried, J. DiGangi, Y. Choi, and H. S. Halliday, 2019a: Forward modeling and optimization of methane emissions in the south central United States using aircraft transects across frontal boundaries. Geophys. Res. Lett., 46, 13564-13573, https://doi.org/10 .1029/2019GL084495.

— coal and natural gas production in southwestern Pennsylvania. Geophys. Res. Lett., 46, 4531-4540, https://doi.org/10.1029/2019GL082131.

_ sions in the southcentral and eastern United States using four seasons of continuous aircraft ethane measurements. J. Geophys. Res. Atmos., 126, e2020JD034194, https://doi.org/10.1029/2020JD034194.

Barnes, E. A., N. Parazoo, C. Orbe, and A. S. Denning, 2016: Isentropic transport and the seasonal cycle amplitude of $\mathrm{CO}_{2}$. J. Geophys. Res. Atmos., 121, 81068124, https://doi.org/10.1002/2016JD025109.

Battle, M., M. L. Bender, P. P. Tans, J. W. C. White, J. T. Ellis, T. Conway, and R. J. Francey, 2000: Global carbon sinks and their variability inferred from atmospheric $\mathrm{O}_{2}$ and $\delta^{13}$ C. Science, 287, 2467-2470, https://doi.org/10.1126/science.287.5462.2467.

Bell, E., and Coauthors, 2020: Evaluation of OCO-2 XCO variability at local and synoptic scales using lidar and in situ observations from the ACT-America campaigns. J. Geophys. Res.Atmos., 125, e2019JD031400,https://doi.org/10.1029/2019JD031400.

Bloom, A. A., and Coauthors, 2017: CMS: Global 0.5-deg wetland methane emissions and uncertainty (WetCHARTs v1.0). ORNL DAAC, accessed 19 September 2021, https://doi.org/10.3334/ORNLDAAC/1502.

Bousquet, P., and Coauthors, 2006: Contribution of anthropogenic and natural sources to atmospheric methane variability. Nature, 443, 439-443, https:// doi.org/10.1038/nature05132.

Brown, V., B. D. Keim, W. D. Kappel, D. M. Hultstrand, A. G. Peyrefitte Jr., A. W. Black, K. M. Steinhilber, and G. A. Muhlestein, 2020: How rare was the August 2016 south-central Louisiana heavy rainfall event? J. Hydrometeor., 21, 773-790, https://doi.org/10.1175/JHM-D-19-0225.1.

Bruhwiler, L. M., and Coauthors, 2017: U.S. CH4 emissions from oil and gas production: Have recent large increases been detected? J. Geophys. Res. Atmos., 122, 4070-4083, https://doi.org/10.1002/2016JD026157.

Butler, M. P., T. Lauvaux, S. Feng, J. Liu, K. W. Bowman, and K. J. Davis, 2020: Atmospheric simulations of total column $\mathrm{CO}_{2}$ mole fractions from global to mesoscale within the Carbon Monitoring System Flux inversion framework. Atmosphere, 11, 787, https://doi.org/10.3390/atmos11080787.

Campbell, J. F., and Coauthors, 2020: Field evaluation of column $\mathrm{CO}_{2}$ retrievals from intensity-modulated continuous-wave differential absorption lidar measurements during the ACT-America campaign. Earth Space Sci., 7, e2019EA000847, https://doi.org/10.1029/2019EA000847.

Chan, D., M. Ishizawa, K. Higuchi, S. Maksyutov, and J. Chen, 2008: Seasonal $\mathrm{CO}_{2}$ rectifier effect and large-scale extratropical atmospheric transport. J. Geophys. Res., 113, D17309, https://doi.org/10.1029/2007JD009443.

Chen, H. W., F. Zhang, T. Lauvaux, K. J. Davis, S. Feng, M. P. Butler, and R. B. Alley, 2019: Characterization of regional-scale $\mathrm{CO}_{2}$ transport uncertainties in an ensemble with flow-dependent transport errors. Geophys. Res. Lett., 46, 4049-4058, https://doi.org/10.1029/2018GL081341.

Chevallier, F., L. Feng, H. Bösch, P. I. Palmer, and P. J. Rayner, 2010: On the impact of transport model errors for the estimation of $\mathrm{CO}_{2}$ surface fluxes from GOSAT observations. Geophys. Res. Lett., 37, L21803, https://doi.org/10.1029/2010GL044652.
Ciais, P., P. Tans, M. Trolier, J. W. C. White, and R. J. Francey, 1995: A large Northern Hemisphere terrestrial $\mathrm{CO}_{2}$ sink indicated by the $13 \mathrm{C} / 12 \mathrm{C}$ ratio of atmospheric $\mathrm{CO}_{2}$. Science, 269, 1098-1102, https://doi.org/10.1126/science.269.5227.1098. — Change 2013: The Physical Science Basis, T. F. Stocker et al., Eds., Cambridge University Press, 465-570.

Conway, T. J., P. P. Tans, L. S. Waterman, and K. W. Thoning, 1994: Evidence for interannual variability of the carbon-cycle from the National Oceanic and Atmospheric Administration Climate Monitoring and Diagnostics Laboratory Global Air Sampling Network. J. Geophys. Res., 99, 22 831-22 855, https://doi. org/10.1029/94JD01951.

Crisp, D., and Coauthors, 2017: The on-orbit performance of the Orbiting Carbon Observatory-2 (OCO-2) instrument and its radiometrically calibrated products. Atmos. Meas. Tech., 10, 59-81, https://doi.org/10.5194/amt-10-59-2017.

Crotwell, A., and M. Steinbacher WMO, Eds., 2018: 19th WMO/IAEA meeting on carbon dioxide, other greenhouse gases and related measurement techniques (GGMT-2017). GAW Rep. 242, 150 pp.

Crowell, S., and Coauthors, 2019: The 2015-2016 carbon cycle as seen from 0CO-2 and the global in situ network. Atmos. Chem. Phys., 19, 9797-9831, https://doi.org/10.5194/acp-19-9797-2019.

Cui, Y. Y., and Coauthors, 2021: Evaluation of CarbonTracker's inverse estimates of North American net ecosystem exchange of $\mathrm{CO}_{2}$ from different observing systems using ACT-America airborne observations. J. Geophys. Res. Atmos., 126, e2020JD034406, https://doi.org/10.1029/2020JD034406.

Davis, K. J., and Coauthors, 2018: ACT-America: L3 merged in situ atmospheric trace gases and flask data, eastern USA. ORNL DAAC, accessed 19 September 2021, https://doi.org/10.3334/ORNLDAAC/1593.

Denning, A. S., I. Y. Fung, and D. Randall, 1995: Latitudinal gradient of atmospheric $\mathrm{CO}_{2}$ due to seasonal exchange with land biota. Nature, 376, 240-243, https://doi.org/10.1038/376240a0.

Díaz-Isaac, L. I., T. Lauvaux, and K. J. Davis, 2018: Impact of physical parameterizations and initial conditions on simulated atmospheric transport and $\mathrm{CO}_{2}$ mole fractions in the US Midwest. Atmos. Chem. Phys., 18, 14813-14835, https:// doi.org/10.5194/acp-18-14813-2018.

— - M. Bocquet, and K. J. Davis, 2019: Calibration of a multi-physics ensemble for estimating the uncertainty of a greenhouse gas atmospheric transport model. Atmos. Chem. Phys., 19, 5695-5718, https://doi.org/10.5194/acp19-5695-2019.

Dlugokencky, E. J., and Coauthors, 2005: Conversion of NOAA atmospheric dry air CH4 mole fractions to a gravimetrically prepared standard scale. J. Geophys. Res., 110, D18306, https://doi.org/10.1029/2005JD006035.

— dangers. Philos. Trans. Roy. Soc., 369A, 2058-2072, https://doi.org/10.1098/ rsta.2010.0341.

Eckl, M., and Coauthors, 2021: Quantifying nitrous oxide emissions in the U.S. Midwest-A top-down study using high resolution airborne in situ observations. Geophys. Res. Lett., 48, e2020GL091266, https://doi.org/10.1029/2020GL091266.

Eldering, A., T. E. Taylor, C. W. O'Dell, and R. Pavlick, 2019: The OCO-3 mission: Measurement objectives and expected performance based on 1 year of simulated data. Atmos. Meas. Tech., 12, 2341-2370, https://doi.org/10.5194/amt-12-2341-2019.

Feng, S., T. Lauvaux, K. Keller, K. J. Davis, P. Rayner, T. Oda, and K. R. Gurney, 2019a: A road map for improving the treatment of uncertainties in highresolution regional carbon flux inverse estimates. Geophys. Res. Lett., 46, 13461-13469, https://doi.org/10.1029/2019GL082987.

_ from biogenic fluxes, transport, and large-scale boundary inflow in atmospheric $\mathrm{CO}_{2}$ simulations over North America. J. Geophys. Res. Atmos., 124, 14325-14346, https://doi.org/10.1029/2019JD031165.

, T. Lauvaux, Z. R. Barkley, K. J. Davis, M. B. Butler, A. Deng, B. Gaudet, and D. Stauffer, 2020: One-way nested (27km, $9 \mathrm{~km}$ and $3 \mathrm{~km}$ ) model output of North American atmospheric $\mathrm{CO}_{2}$ simulation (full WRF-chem output). Subset used: 1 July 2016-31 July 2019. Pennsylvania State University Data Commons, 19 September 2021, https://doi.org/10.26208/49kd-b637. 
_- C. A. Williams, K. J. Davis, Y. Zhou, I. Baker, Z. R. Barkley, and D. Wesloh, 2021: Joint $\mathrm{CO}_{2}$ mole fraction and flux analysis confirms missing processes in CASA terrestrial carbon uptake over North America. Global Biogeochem. Cycles, 35, e2020GB006914, https://doi.org/10.1029/2020GB006914.

Fisher, J. B., D. N. Huntzinger, C. R. Schwalm, and S. Sitch, 2014: Modeling the terrestrial biosphere. Annu. Rev. Environ. Resour., 39, 91-123, https://doi. org/10.1146/annurev-environ-012913-093456.

Friedlingstein, P., M. Meinshausen, V. K. Arora, C. D. Jones, A. Anav, S. K. Liddicoat, and R. Knutti, 2014: Uncertainties in CMIP5 climate projections due to carbon cycle feedbacks. J. Climate, 27, 511-526, https://doi.org/10.1175/JCLI-D-12-00579.1.

Gaudet, B. J., K. J. Davis, S. Pal, A. R. Jacobson, A. Schuh, T. Lauvaux, S. Feng, and E. V. Browell, 2021: Regional-scale, sector-specific evaluation of global $\mathrm{CO}_{2}$ inversion models using aircraft data from the ACT-America project. J. Geophys. Res. Atmos., 126, e2020JD033623, https://doi.org/10.1029/2020JD033623.

Gerbig, C., S. Körner, and J. C. Lin, 2008: Vertical mixing in atmospheric tracer transport models: Error characterization and propagation. Atmos. Chem. Phys. , 8, 591-602, https://doi.org/10.5194/acp-8-591-2008.

Gerken, T., S. Feng, K. Keller, T. Lauvaux, J. P. DiGangi, Y. Choi, B. Baier, and K. J. Davis, 2021: Examining $\mathrm{CO}_{2}$ model observation residuals and their implications for carbon fluxes and transport using ACT-America observations. J. Geophys. Res. Atmos., 126, e2020JD034481, https://doi.org/10.1029 /2020JD034481.

Gurney, K. R. and Coauthors, 2002: Towards robust regional estimates of $\mathrm{CO}_{2}$ sources and sinks using atmospheric transport models. Nature, 415, 626-630, https://doi.org/10.1038/415626a.

Gregory, J. M., C. D. Jones, P. Cadule, and P. Friedlingstein, 2009: Quantifying carbon cycle feedbacks. J. Climate, 22, 5232-5250, https://doi. org/10.1175/2009JCLI2949.1.

Hazan, L., J. Tarniewicz, M. Ramonet, O. Laurent, and A. Abbaris, 2016: Automatic processing of atmospheric $\mathrm{CO}_{2}$ and $\mathrm{CH}_{4}$ mole fractions at the ICOS Atmosphere Thematic Centre. Atmos. Meas. Tech., 9, 4719-4736, https://doi. org/10.5194/amt-9-4719-2016.

Holden, P. B., and Coauthors, 2018: Climate-carbon cycle uncertainties and the Paris Agreement. Nat. Climate Change, 8, 609-613, https://doi.org/10.1038/ s41558-018-0197-7.

Hu, H., and Coauthors, 2018: Toward global mapping of methane with TROPOMl: First results and intersatellite comparison to GOSAT. Geophys. Res. Lett., 45, 3682-3689, https://doi.org/10.1002/2018GL077259.

$\mathrm{Hu}$ L., and Coauthors, 2019: Enhanced North American carbon uptake associated with El Niño. Sci. Adv., 5 eaaw0076, https://doi.org/10.1126/sciadv.aaw0076.

$\mathrm{Hu}, \mathrm{X} .-\mathrm{M}$. , and Coauthors, 2021: Implementation of improved parameterization of terrestrial flux in WRF-VPRM improves the simulation of nighttime $\mathrm{CO}_{2}$ peaks and a daytime $\mathrm{CO}_{2}$ band ahead of a cold front. J. Geophys. Res. Atmos., 126, e2020JD034362, https://doi.org/10.1029/2020JD034362.

Huntzinger, D. N., and Coauthors, 2012: North American Carbon Program (NACP) regional interim synthesis: Terrestrial biosphere model intercomparison. Ecol. Modell., 232, 144-157, https://doi.org/10.1016/j.ecolmodel.2012.02.004.

_ to environmental drivers undermines carbon-climate feedback predictions. Sci. Rep., 7, 4765, https://doi.org/10.1038/s41598-017-03818-2.

Hurwitz, M. D., D. M. Ricciuto, K. J. Davis, W. Wang, C. Yi, M. P. Butler, and P. S. Bakwin, 2004: Advection of carbon dioxide in the presence of storm systems over a northern Wisconsin forest. J. Atmos. Sci., 61, 607-618, https://doi. org/10.1175/1520-0469(2004)061<0607:TOCDIT>2.0.CO;2.

IPCC, 2013: Climate Change 2013: The Physical Science Basis. Cambridge University Press, 1535 pp., https://doi.org/10.1017/CB09781107415324.

Kostinek, J., and Coauthors, 2019: Modification, characterization and evaluation of a quantum/interband cascade laser spectrometer for simultaneous airborne in situ observation of $\mathrm{CH}_{4^{\prime}} \mathrm{C}_{2} \mathrm{H}_{6^{\prime}} \mathrm{CO}_{2^{\prime}} \mathrm{CO}$ and $\mathrm{N}_{2} \mathrm{O}$. Atmos. Meas. Tech., 12, 1767-1783, https://doi.org/10.5194/amt-12-1767-2019.

Kuze, A., and Coauthors, 2016: Update on GOSAT TANSO-FTS performance, operations, and data products after more than 6 years in space. Atmos. Meas. Tech., 9, 2445-2461, https://doi.org/10.5194/amt-9-2445-2016.
Lan, X., and Coauthors, 2019: Long-term measurements show little evidence for large increases in total U.S. methane emissions over the past decade. Geophys. Res. Lett., 46, 4991-4999, https://doi.org/10.1029/2018GL081731.

Lauvaux, T., and K. J. Davis, 2014: Planetary boundary layer errors in mesoscale inversions of column-integrated $\mathrm{CO}_{2}$ measurements. J. Geophys. Res. Atmos., 119, 490-508, https://doi.org/10.1002/2013JD020175.

- - and Coauthors, 2012: Constraining the $\mathrm{CO}_{2}$ budget of the corn belt: Exploring uncertainties from the assumptions in a mesoscale inverse system. Atmos. Chem. Phys., 12, 337-354, https://doi.org/10.5194/acp-12-337-2012.

— L. I. Díaz-Isaac, M. Bocquet, and N. Bousserez, 2019: Diagnosing spatial error structures in $\mathrm{CO}_{2}$ mole fractions and $\mathrm{XCO}_{2}$ column mole fractions from atmospheric transport. Atmos. Chem. Phys., 19, 12 007-12 024, https://doi. org/10.5194/acp-19-12007-2019.

Liu, J., and Coauthors, 2017: Contrasting carbon cycle responses of the tropical continents to the 2015-2016 El Nino. Science, 358, eaam5690, https://doi. org/10.1126/science.aam5690.

Machida, T., and Coauthors, 2008: Worldwide measurements of atmospheric $\mathrm{CO}_{2}$ and other trace gas species using commercial airlines. J. Atmos. Oceanic Technol., 25, 1744-1754, https://doi.org/10.1175/2008JTECHA1082.1.

Marquis, M., and P. Tans, 2008: Carbon crucible. Science, 320, 460-461, https:// doi.org/10.1126/science.1156451.

Maasakkers, J. D., and Coauthors, 2016: Gridded National Inventory of U.S. Methane Emissions, Environ. Sci. Technol., 50, 13123-13133, https://doi. org/10.1021/acs.est.6b02878.

Masarie, K. A., W. Peters, A. R. Jacobson, and P. P. Tans, 2014: ObsPack: A framework for the preparation, delivery, and attribution of atmospheric greenhouse gas measurements. Earth Syst. Sci. Data, 6, 375-384, https://doi.org/10.5194/ essd-6-375-2014.

McGill, M. J., and Coauthors, 2004: Combined lidar-radar remote sensing: Initial results from CRYSTAL-FACE. J. Geophys. Res., 109, D07203, https://doi. org/10.1029/2003JD004030.

Michalak, A. M., and Coauthors, 2011: A U.S. carbon cycle science plan. UCAR Rep., 81 pp., www.carboncyclescience.us/sites/default/files/documents/ USCarbonCycleSciencePlan-2011.pdf.

Miles, N. L., S. J. Richardson, K. J. Davis, T. Lauvaux, A. E. Andrews, T. O. West, V. Bandaru, and E. R. Crosson, 2012: Large amplitude spatial and temporal gradients in atmospheric boundary layer $\mathrm{CO}_{2}$ mole fractions detected with a tower-based network in the U.S. upper Midwest. J. Geophys. Res., 117, G01019, https://doi.org/10.1029/2011JG001781.

_ _ D. K. Martins, K. J. Davis, T. Lauvaux, B. J. Haupt, and S. K. Miller, 2018: ACT-America: $\mathrm{L} 2$ in situ $\mathrm{CO}_{2}, \mathrm{CO}$, and $\mathrm{CH} 4$ concentrations from towers, eastern USA. ORNL DAAC, accessed 19 September 2021, https://doi.org/10.3334/ ORNLDAAC/1568.

Miller, S. M., and Coauthors, 2013: Anthropogenic emissions of methane in the United States. Proc. Natl. Acad. Sci. USA, 110, 20018-20022, https://doi. org/10.1073/pnas.1314392110.

Montzka, S. A., and Coauthors, 2011: Non- $\mathrm{CO}_{2}$ greenhouse gases and climate change. Nature, 476, 43-50, https://doi.org/10.1038/nature10322.

Moore, B., III, and Coauthors, 2018: The potential of the Geostationary Carbon Cycle Observatory (GeoCarb) to provide multi-scale constraints on the carbon cycle in the Americas. Front. Environ. Sci., 6, 109, https://doi.org/10.3389/ fenvs.2018.00109.

Myhre, G. D., and Coauthors, 2013: Anthropogenic and natural radiative forcing. Climate Change 2013: The Physical Science Basis, T. F. Stocker et al., Eds., Cambridge University Press, 659-740.

Nalli, N. R., and Coauthors, 2020: Validation of carbon trace gas profile retrievals from the NOAA-Unique Combined Atmospheric Processing System for the Cross-Track Infrared Sounder. Remote Sens., 12, 3245, https://doi.org/10.3390/rs12193245.

Nisbet, E. G., E. J. Dlugokencky, and P. Bousquet, 2014: Methane on the riseAgain. Science, 343, 493-495, https://doi.org/10.1126/science.1247828.

O'Dell, C. W., and Coauthors, 2018: Improved retrievals of carbon dioxide from Orbiting Carbon Observatory-2 with the version 8 ACOS algorithm. Atmos. Meas. Tech., 11, 6539-6576, https://doi.org/10.5194/amt-11-6539-2018. 
Ogle, S. M., and Coauthors, 2015: An approach for verifying biogenic greenhouse gas emissions inventories with atmospheric $\mathrm{CO}_{2}$ concentration data. Environ. Res. Lett., 10, 034012, https://doi.org/10.1088/17489326/10/3/034012.

Pal, S., and K. J. Davis, 2020: ACT-America campaign catalogue. ORNL DAAC, https://actamerica.ornl.gov/campaigns.html.

— across summer frontal boundaries in the eastern United States. J. Geophys. Res. Atmos., 125, e2019JD030526, https://doi.org/10.1029 I2019JD030526.

_ , and Coauthors, 2020b: ACT-America: CPL-derived atmospheric boundary layer top height, eastern US, 2016-2018. ORNL DAAC, accessed 19 September 2021, https://doi.org/10.3334/ORNLDAAC/1825.

Parazoo, N. C., A. S. Denning, S. R. Kawa, K. D. Corbin, R. S. Lokupitiya, and I. T. Baker, 2008: Mechanisms for synoptic variations of atmospheric $\mathrm{CO}_{2}$ in North America, South America and Europe. Atmos. Chem. Phys., 8, 7239-7254, https://doi.org/10.5194/acp-8-7239-2008.

_ - J. A. Berry, A. Wolf, D. A. Randall, S. R. Kawa, 0. Pauluis, and S. C. Doney, 2011: Moist synoptic transport of $\mathrm{CO}_{2}$ along the mid-latitude storm track. Geophys. Res. Lett., 38, 2011GL047238, https://doi. org/10.1029/2011GL047238.

_ _ - S. R. Kawa, S. Pawson, and R. Lokupitiya, 2012: $\mathrm{CO}_{2}$ flux estimation errors associated with moist atmospheric processes. Atmos. Chem. Phys., 12, 6405-6416, https://doi.org/10.5194/acp-12-6405-2012.

- and Coauthors, 2021: Covariation of airborne biogenic tracers $\left(\mathrm{CO}_{2}, \mathrm{COS}\right.$, and $\mathrm{CO}$ ) supports stronger than expected growing season photosynthetic uptake in the southeastern US. Global Biogeochem. Cycles, in press.

Peters, W., and Coauthors, 2007: An atmospheric perspective on North American carbon dioxide exchange: CarbonTracker. Proc. Natl. Acad. Sci. USA, 104, 18925-18930, https://doi.org/10.1073/pnas.0708986104.

Peylin, P., and Coauthors, 2013: Global atmospheric carbon budget: Results from an ensemble of atmospheric $\mathrm{CO}_{2}$ inversions. Biogeosciences, 10, 6699-6720, https://doi.org/10.5194/bg-10-6699-2013.

Pickett-Heaps, C. A., and Coauthors, 2011: Atmospheric $\mathrm{CO}_{2}$ inversion validation using vertical profile measurements: Analysis of four independent inversion models. J. Geophys. Res., 116, D12305, https://doi.org/10.1029 /2010JD014887.

Pisso, I., and Coauthors, 2019: The Lagrangian particle dispersion model FLEXPART version 10.4. Geosci. Model Dev., 12, 4955-4997, https://doi.org/10.5194/ gmd-12-4955-2019.

Polonsky, I. N., and Coauthors, 2014: Performance of a geostationary mission, geoCARB, to measure $\mathrm{CO}_{2}, \mathrm{CH}_{4}$ and $\mathrm{CO}$ column-averaged concentrations. Atmos. Meas. Tech., 7, 959-981, https://doi.org/10.5194/amt-7-959-2014.

Prather, M. J., and Coauthors, 2018: How well can global chemistry models calculate the reactivity of short-lived greenhouse gases in the remote troposphere, knowing the chemical composition. Atmos. Meas. Tech., 11, 2653-2668, https://doi.org/10.5194/amt-11-2653-2018.

Samaddar, A., S. Feng, T. Lauvaux, Z. R. Barkley, S. Pal, and K. J. Davis, 2021: Carbon dioxide distribution, origins, and transport along a frontal boundary during summer in mid-latitudes. J. Geophys. Res. Atmos., 126, e2020JD033118, https://doi.org/10.1029/2020JD033118.

Saunois, M, and Coauthors, 2016: The global methane budget 2000-2012. Earth Syst. Sci. Data, 8, 697-751, https://doi.org/10.5194/essd-8-697-2016.

Schuck, T. J., C. A. M. Brenninkmeijer, F. Slemr, I. Xueref-Remy, and A. Zahn, 2009: Greenhouse gas analysis of air samples collected onboard the CARIBIC passenger aircraft. Atmos. Meas. Tech., 2, 449-464, https://doi.org/10.5194/ amt-2-449-2009.

Schuh, A. E., and Coauthors, 2013: Evaluating atmospheric $\mathrm{CO}_{2}$ inversions at multiple scales over a highly-inventoried agricultural landscape. Global Change Biol., 19, 1424-1439, https://doi.org/10.1111/gcb.12141.

— , and Coauthors, 2019: Quantifying the impact of atmospheric transport uncertainty on $\mathrm{CO}_{2}$ surface flux estimates. Global Biogeochem. Cycles, 33, 484-500, https://doi.org/10.1029/2018GB006086.
Schuldt, K., and Coauthors, 2020: Multi-laboratory compilation of atmospheric carbon dioxide data for the period 1957-2019; obspack_co2_1_ GLOBALVIEWplus_v6.0_2020-09-11. NOAA Global Monitoring Laboratory, accessed 19 September 2021, https://doi.org/10.25925/20200903.

Schwalm, C. R., and Coauthors, 2015: Toward "optimal" integration of terrestrial biosphere models. Geophys. Res. Lett., 42, 4418-4428, https://doi. org/10.1002/2015GL064002.

Stein, A. F., R. R. Draxler, G. D. Rolph, B. J. B. Stunder, M. D. Cohen, and F. Ngan, 2015: NOAA's HYSPLIT atmospheric transport and dispersion modeling system. Bull. Amer. Meteor. Soc., 96, 2059-2077, https://doi.org/10.1175/BAMS-D-14-00110.1.

Stephens, B. B., and Coauthors, 2007: Weak northern and strong tropical land carbon uptake from vertical profiles of atmospheric $\mathrm{CO}_{2}$. Science, 316, 1732 1735, https://doi.org/10.1126/science.1137004.

Sweeney, C., and Coauthors, 2015: Seasonal climatology of $\mathrm{CO}_{2}$ across North America from aircraft measurements in the NOAA/ESRL Global Greenhouse Gas Reference Network. J. Geophys. Res. Atmos., 120, 5155-5190, https://doi. org/10.1002/2014JD022591.

Tans, P. P., I. Y. Fung, and T. Takahashi, 1990: Observational constraints on the global atmospheric $\mathrm{CO}_{2}$ budget. Science, 247, 1431-1438, https://doi. org/10.1126/science.247.4949.1431.

Thompson, R., and Coauthors, 2016: Top-down assessment of the Asian carbon budget since the mid 1990s. Nat. Commun., 7, 10724, https://doi.org/10.1038/ ncomms10724.

Turnbull, J. C., and Coauthors, 2015: Toward quantification and source sector identification of fossil fuel $\mathrm{CO}_{2}$ emissions from an urban area: Results from the INFLUX experiment. J. Geophys. Res. Atmos., 120, 292-312, https://doi. org/10.1002/2014JD022555.

Turner, A. J., C. Frankenberg, and E. A. Kort, 2019: Interpreting contemporary trends in atmospheric methane. Proc. Natl. Acad. Sci. USA, 116, 2805-2813, https://doi.org/10.1073/pnas.1814297116.

USGCRP, 2018: Second State of the Carbon Cycle Report (SOCCR2): A sustained assessment report. U.S. Global Change Research Program Rep., 878 pp.

Vermote, E., 2019: NOAA Climate Data Record (CDR) of AVHRR normalized difference vegetation index (NDVI), version 5. NOAA National Centers for Environmental Information, accessed 6 December, 2020, https://doi.org/10.7289/ V5ZG6QH9.

Wei, Y., and Coauthors, 2021: Atmospheric Carbon and Transport-America (ACTAmerica) datasets: Description, management, and delivery. Earth Space Sci., 8, e2020EA001634, https://doi.org/10.1029/2020EA001634.

Weibring, P., and Coauthors, 2020: Autonomous airborne mid-infrared spectrometer for high-precision measurements of ethane during the NASA ACTAmerica studies. Atmos. Meas. Tech., 13, 6095-6112, https://doi.org/10.5194/ amt-13-6095-2020.

Wesloh, D., T. Lauvaux, and K. J. Davis, 2020: Development of a mesoscale inversion system for estimating continental-scale $\mathrm{CO}_{2}$ fluxes. J. Adv. Model. Earth Syst., 12, e2019MS001818, https://doi.org/10.1029/2019MS001818.

Wunch, D., and Coauthors, 2011: The total carbon column observing network. Philos. Trans. Roy. Soc., 369A, 2087-2112, https://doi.org/10.1098/ rsta.2010.0240.

— (0CO-2) XCO measurements with TCCON. Atmos. Meas. Tech., 10, 22092238, https://doi.org/10.5194/amt-10-2209-2017.

Yin, Y., and Coauthors, 2020: Cropland carbon uptake delayed and reduced by 2019 Midwest floods. AGU Adv., 1, e2019AV000140, https://doi. org/10.1029/2019AV000140.

Yokota, T., Y. Yoshida, N. Eguchi, Y. Ota, T. Tanaka, H. Watanabe, and S. Maksyutov, 2009: Global Concentrations of $\mathrm{CO}_{2}$ and $\mathrm{CH}_{4}$ retrieved from GOSAT: First preliminary results. SOLA, 5, 160-163, https://doi.org/10.2151/sola.2009041.

Zhou, Y., and Coauthors, 2020: A multiyear gridded data ensemble of surface biogenic carbon fluxes for North America: Evaluation and analysis of results. J. Geophys. Res. Biogeosci., 125, e2019JG005314, https://doi. org/10.1029/2019JG005314. 